\title{
EL EMERGENTISMO HUMANISTA DE JAVIER MONSERRAT
}

\author{
CARLOS BEORLEGUI \\ Universidad de Deusto, Bilbao
}

\begin{abstract}
RESUMEN: J. Monserrat constituye el representante más significativo y consistente del paradigma emergentista en nuestro entorno cultural, defendiendo un emergentismo humanista, que ha ido profundizando desde el nivel de los engramas neuronales hasta adherirse a las tesis de la neurología cuántica de Penrose y Hameroff. A lo largo de este artículo se presentan los principales planteamientos defendidos por J. Monserrat, dentro del horizonte del amplio paradigma del emergentismo sistémico, advirtiéndose como dicho paradigma le permite defender de un modo más adecuado un modelo antropológico humanista y creyente.
\end{abstract}

PALABRAS CLAVE: emergentismo, emergentismo humanista, reduccionismo materialista, engramas neuronales, neurología cuántica, microtúbulos, citoesqueleto nuclear, hiperformalización.

\section{The humanist emergentism of Javier Monserrat}

ABSTRACT: J. Monserrat is the most significant and consistent representative of the emergentist paradigm in our cultural context. He defends a humanist emergentism, which he has deepened from the level of neuronal engrams to later agree with the postulates on quantum neurology by Penrose and Hameroff. This article will present the main arguments supported by J. Monserrat, within the context of the ample paradigm of systemic emergentism. It will show how this paradigm allows him to defend a humanist and believing anthropological model in a more adequate way.

KEY WORDS: emergentism, humanist emergentism, materialist reductionism, neuronal engrams, quantum neurology, microtubules, nuclear cytoskeleton, hiperformalization.

\section{Presentación}

El emergentismo como paradigma científico, y sobre todo como fórmula explicativa de las relaciones mente-cuerpo, dentro de una visión unitaria del ser humano, se está convirtiendo en la postura más respaldada, tras ir superando antiguos reparos e incomprensiones. En nuestro entorno, J. Monserrat ha sido desde hace ya varias décadas uno de los primeros y más claros defensores y exponentes del paradigma emergentista. El mérito de J. Monserrat está en haber profundizado permanentemente su postura, permaneciendo al tanto de las múltiples aportaciones que se están aportando desde todos los ámbitos de las ciencias y de la filosofía, especialmente desde la neurociencia cuántica.

En estas páginas, que en cierta medida constituyen un homenaje al esfuerzo investigador y divulgador que J. Monserrat ha estado realizando a lo largo de las últimas décadas en el ámbito de la filosofía de la mente y de las 
relaciones mente-cuerpo, vamos a presentar el desarrollo de su pensamiento sobre este punto. La exposición constará de una primera parte en la que presentaremos, de forma breve y como horizonte panorámico, el itinerario intelectual de nuestro autor, para posteriormente presentar las líneas maestras de su emergentismo humanista, presentando anteriormente una visión panorámica del paradigma emergentista, tanto en su vertiente histórica como sistemática. Estas reflexiones quieren ser una ampliación de otros trabajos anteriores, en los que he presentado el emergentismo de J. Monserrat, en contraste con un amplio panorama de teóricos que también se sitúan dentro de esta postura filosófica ${ }^{1}$.

\section{La trayectoria intelectual de J. Monserrat}

Una de las características del talante intelectual de J. Monserrat, sacerdote jesuita, es la amplitud de sus intereses intelectuales, fruto de una amplia y sólida formación, así como de una no menor amplitud de su abanico de lecturas e investigaciones. Amplitud que le permite moverse con fluidez y acierto entre la ciencia, la filosofía y la teología, convirtiéndose sin ninguna duda en uno de los intelectuales de nuestro ámbito filosófico que mejor ejerce el importante rol de moverse interdisciplinariamente y dialogar entre saberes fronterizos, buscando siempre las complicidades entre ellos, y los mutuos enriquecimientos, sin detenerse en emitir superficiales condenas y descalificaciones.

Ya desde sus años de formación, se ha movido entre la teología, la filosofía y diversos ámbitos científicos, como un auténtico humanista del presente. Ha dictado cursos de Epistemología, Psicología de la cultura, Filosofía de la historia, Filosofía política, Filosofía de la religión, etc., a lo largo de sus muchos años como profesor titular de la Universidad Autónoma de Madrid, así como de la Universidad Pontificia de Comillas. Además, como consecuencia de su interés por la psicología cognitiva y ciencia de la visión, permaneció durante un año sabático como visiting researcher en el Institute of Cognitive Studies de la Universidad de California en Berkeley (1992-1993). Realizó también estudios de teología en Alemania, en la Philosophische-Teologische Hochschule Sankt Georgen, de Frankfurt am Main, duran los años de 1971 a 1974.

Fruto de esta amplitud de intereses y de inquietudes intelectuales son sus múltiples publicaciones, en las que busca el análisis de los diversos planteamientos investigados, así como la visión sistémica de los problemas. Entre sus textos más fundamentales hay que resaltar los siguientes: Existencia, mundanidad, cristianismo. Introducción filosófico-antropológica a la teología

1 Cfr. Beorlegui, C., «Los emergentismos sistémicos: un modelo fructífero para el problema mente-cuerpo», Pensamiento, 62(2006), n 234, 391-439; Id, «Emergentism», Pensamiento, 65 (2009), no 246, Serie Especial, nº 3, pp. 881-914. 
fundamental ${ }^{2}$, Epistemología evolutiva y teoría de la ciencia ${ }^{3}$, La percepción visual. La arquitectura del psiquismo desde el enfoque de la percepción visual', Dédalo. La revolución americana del siglo XXI (novela) ${ }^{5}$, Hacia un mundo nuevo. Filosofía Política del protagonismo histórico emergente de la sociedad civil ${ }^{6}, \mathrm{Ha}$ cia un nuevo concilio. El paradigma de la modernidad en la Era de la Ciencia ${ }^{7}$. Tiene en perspectiva un nuevo libro en vías de publicación, que tendrá por título El Gran Enigma. Ateos y creyentes ante la incertidumbre del más-allá.

De entre estos libros señalados, cabe destacar la trilogía formada por Dédalo, Hacia un mundo nuevo, y Hacia un nuevo concilio, en la que expone de forma ambiciosa, pero bien sistematizada y justificada, su pensamiento científico, filosófico y teológico sobre nuestro mundo, necesitado según J. Monserrat de una cosmovisión renovada, en la que se conjuguen adecuadamente las amplias y revolucionarias aportaciones de las ciencias actuales, con una visión filosófica y teológica, conjunción que ponga al día una teología necesitada tanto de una vuelta al evangelio como de un diálogo con la mentalidad ilustrada del presente. El nuevo libro que está preparando, El Gran Enigma, apuntan en la misma dirección.

Junto a estos libros, su producción intelectual se ha ido desplegando a través de una amplia y selecta colección de artículos, publicados en diversas revistas, pero sobre todo en Pensamiento, revista de la que ha sido su director durante 25 años (hasta 2011), así como editor de los seis volúmenes extraordinarios (de la propia revista Pensamiento), bajo el título genérico de Ciencia, Filosofía y Religión (entre 2007 y 2011). También ha sido uno de los creadores y dinamizadores de la Cátedra Ciencia, Tecnología y Religión, en la Escuela Superior de Ingeniería de la Universidad de Comillas, y de la revista digital Tendencias 21 (en su sección Tendencias 21 de las Religiones), plataforma donde se mantiene un diálogo actualizado y permanente entre ciencia, humanidades y religiones, a través de artículos, recensiones, y diversos documentos, que tratan de presentar al gran público lo más actual e interesante de las cuestiones que afectan al diálogo entre ciencia, filosofía y religión. Ha participado también en el programa Sophia de la fundación Templeton, institución estadounidense dedicada a financiar, premiar y promover los estudios referentes al diálogo entre ciencia y religión. Y sobre estos temas ha publicado varios artículos en la revista Pensamiento, cuyos títulos indicaremos más adelante.

Entre los artículos publicados en Pensamiento, cabe destacar, en primer lugar, y sin ánimo de ser exhaustivo, los que ha dedicado a la presentación de las teorías de diversos autores centrales en la filosofía de la mente, como

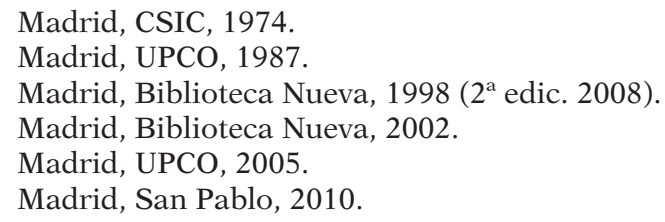


«Francis Crick y la emergencia de la conciencia visual» ${ }^{8}$, «Penrose y la mente computacional» ${ }^{9}$, «Penrose y el enigma cuántico de la conciencia» ${ }^{10}$, «Engramas neuronales y teoría de la mente» ${ }^{11}$, «John Searle en la discusión sobre la conciencia ${ }^{12}$, «Teoría de la mente en Antonio Damasio» ${ }^{13}$, «Génesis evolutiva de la representación y del conocimiento» ${ }^{14}$, «Gerald M. Edelman y su antropología neurológica: Presentación y discusión de su teoría de la mente» ${ }^{15}$, «Neural Networks and Quantum Neurology: Speculativ Heuristic Towards the Arquitecture of Psychism ${ }^{16}$, e «Introduction to Final Debate. Holistic Approach in Biology and Neuroscience» ${ }^{17}$.

Cabe igualmente destacar, en segundo lugar, la colección de artículos dedicados a presentar las ideas de varios autores recientes que se han convertido en referencias internacionales sobre el diálogo entre la ciencia y la fe ${ }^{18}$ : «Ciencia, filosofía del proceso y Dios en Ian Barbour»" ${ }^{19}$, "Ciencia, bioquímica y panenteísmo en Arthur Peacocke» ${ }^{20}$, «John Polkinghorne, ciencia y religión desde la física teórica ${ }^{21}$. Dentro de la temática sobre el diálogo entre ciencia y fe, también ha publicado otras contribuciones como «Kenosis: Towards a New Theology of Science»22, «-Dawkins: The God Delusion. The Criticism of Religion which has Become a Polemic Without Limits»" ${ }^{23}$, "Alfred N. Whitehead on Process Philosophy and Theology: Cosmos and Kenosis of Divinity» ${ }^{24}$, «Mathematical Models Beyond Space and Time: Michael Heller Reflects on de "Big Questions" of Cosmology» ${ }^{25}$, «La obra de Hawking confirma el enigma metafísico del universo. Una especulación posible: Hawking y la cosmología de los multiversos ${ }^{26}$, «Los multiversos cíclicos de Roger Penrose. Hawkin y

8 Pensamiento, 52 (1996), nº 203, pp. 241-252.

9 Pensamiento, 55 (1999), $\mathrm{n}^{\circ}$ 212, pp. 176-216.

10 Pensamiento, 56 (2000), $\mathrm{n}^{\circ} 215$, pp. 177-208.

11 Pensamiento, 57 (2001), $\mathrm{n}^{\circ}$ 218, pp. 177-211.

12 Pensamiento, 58 (2002), n $\mathrm{n}^{\circ} 220$, pp. 143-159.

13 Pensamiento, 59 (2003), no 224, pp. 177-213.

14 Cfr. Martínez-Freire, Pascual F., Cognición y representación, Contrastes, Suplemento 10 (Málaga), 2005, pp. 51-70.

15 Pensamiento, 62 (2006), pp. 141-170.

16 Cfr. Mira, J./Alvarez, J. R. (eds.), Bio-inspired Modeling of Cognitive Tasks, Berlin-Heidelberg, Springer Verlag, 2007, Part. I, pp. 1-20.

17 Pensamiento, 67 (2011), Serie Especial, no 5 (2011), pp. 733-743.

18 Los tres artículos aparecieron también en inglés, en Heller Del Riego, Christine (ed.), God Seen by Science: Anthropic Evolution of the Universe, Madrid, UPCO/Cátedra CTR, 2008, pp. texto editado como contribución de Sophia-Iberia a la Conferencia Metanexus (Fundación Templeton) celebrada en la Universidad de Comillas de Madrid, en 2008.

19 Pensamiento, 60 (2004), no 226, pp. 33-66.

20 Pensamiento, 61 (2005), no 229, pp. 59-76.

21 Pensamiento, 61 (2005), no 231, pp. 363-393.

22 Pensamiento, 63 (2007), $\mathrm{n}^{\circ}$ 238, Serie Especial, $\mathrm{n}^{\circ} 1$ (2007), pp. 637-658.

23 Pensamiento, 63 (2007), $\mathrm{n}^{\circ}$ 238, Serie Especial, $\mathrm{n}^{\circ} 1$ (2007), pp. 807-813.

24 Pensamiento, 64 (2008), Serie Especial, $\mathrm{n}^{\circ} 2$ (2008), pp. 815-845.

25 Pensamiento, 64 (2008), Serie Especial, $n^{\circ} 2$ (2008), pp. 1087-1092.

26 Pensamiento, 67 (2011), Serie Especial, no 5 (2011), pp. 1133-1145. 
Penrose, dos modelos alternativos de multiversos $»^{27}$, «Sam Harris: La promoción del humanismo exige el fin de la fe ${ }^{28}$, «Christopher Hitchens: Un alegado racional y moral sobre la religión ${ }^{29}, \mathrm{y}$ "Antony Flew: Del ateísmo al teísmo por la razón científica ${ }^{30}$.

Es digno también de resaltarse el hecho de que J. Monserrat perteneció al selecto grupo de discípulos conformado alrededor del magisterio de X. Zubiri, participando en diversas ocasiones de las enriquecedoras sesiones del denominado Seminario de X. Zubiri. Y aunque no se has remitido en sus escritos a ser un mero comentarista y contagiador de su filosofía, siempre se ha preocupado por hacer fructíferas las aportaciones del maestro en las diferentes temáticas filosóficas que ha cultivado, para dejar constancia de su permanente capacidad sugeridora, así como de su indiscutible actualidad. La presencia y el contagio que el pensamiento zubiriano ha dejado en Monserrat se advierte en casi todas sus obras, pero de modo especial en varios de sus escritos, dedicados a mostrar la relación del pensamiento zubiriano con los enfoques más actuales de las ciencias y de la filosofía, como es el caso de «La conexión fundamental de $\mathrm{Zu}$ biri con las ciencias humanas ${ }^{31}, \mathrm{y}$ "La mente natural y el mundo de la ciencia: el mundo de objetos en el campo de realidad $\aleph^{32}$. Como veremos más adelante, la tesis zubiriana de la hiperformalización para explicar el proceso de hominización y la emergencia de la mente humana, constituye un elemento clave del emergentismo humanista de J. Monserrat.

Dado que el paradigma emergentista es un complejo teórico que posee su complejidad, variaciones y diferencias, necesitamos presentar como horizonte previo sus rasgos fundamentales, antes de exponer las claves del emergentismo humanista de Monserrat.

\section{Un ACERCAMIENTO AL EMERGENTISMO}

J. Monserrat se adscribió al paradigma emergentista desde sus primeros escritos, perfeccionando su postura de forma progresiva por influjo de una serie de autores en los que ha visto aspectos relevantes y determinantes, que están haciendo más precisa y concreta esta teoría, que en sí misma no pasa de ser un modelo de investigación y de comprensión de la realidad, necesitada, por ello, de ser validada a través de programas concretos de investigación y de demostración objetiva.

27 Pensamiento, 67 (2011), Serie Especial, no 5 (2011), pp. 1147-1156.

28 Pensamiento, 69 (2013), Serie Especial, no 6 (2013), pp. 1069-1078.

29 Pensamiento, 69 (2013), Serie Especial, no 6 (2013), pp. 1079-1085.

30 Pensamiento, 69 (2013), Serie Especial, no 6 (2013), pp. 1087-1101.

31 Cfr. Nicolás, J. A./Barroso, O. (eds.), Balance y perspectivas de la filosofía de Zubiri, Granada, Comares, 2004, pp. 501-514.

32 Pensamiento, 65 (2009), Serie Especial, no 3 (2009), pp. 579-591. 
Antes de ir desgranando los planteamientos de Monserrat, con sus sucesivos avances y concreciones, nos vamos a detener en presentar en líneas generales el paradigma emergentista, su historia y su presencia en los diversos ámbitos de la realidad, sobre todo en el ámbito de la filosofía de la mente.

\subsection{El paradigma emergentista.}

El emergentismo es un modelo teórico de entender la realidad que puede aplicarse a muchos ámbitos de la misma. Representa un contrapeso fundamental a la preponderancia del reduccionismo, que propugna como modelo explicativo de cualquier realidad el desmembramiento en sus diversas partes, hasta llegar a sus partículas más elementales. Por eso, la postura reduccionista defiende que todo lo que existe puede explicarse desde un único y último nivel de la realidad, la física. En cambio, el paradigma emergentista entiende que la estrategia reduccionista no explica más que una faceta o dimensión de la realidad, la que va del todo a las partes, olvidando que la realidad es dinámica, y desde el origen del universo, el big bang, se ha ido configurando como una historia de progresiva complejificación, en la que las partículas elementales se han ido organizando para conformar estructuras nuevas, cada vez más complejas, hasta llegar a las estrellas, planetas y galaxias, y, dentro de nuestro planeta (puede que otros similares dentro de la inmensa extensión del universo), la materia inanimada se ha estructurado de tal modo que ha emergido la vida, con toda su maravillosa variedad y complejidad, hasta hacer emerger la vida autoconsciente, en el género humano.

Por eso, aunque los modelos reduccionista y emergentista suelen presentarse a veces como modelos excluyentes e irreconciliables, y en sus versiones extremas es posible que así sea, es más adecuado entenderlos no tanto como excluyentes, sino como complementarios. Aunque depende también de los diversos tipos de reduccionismos (ontológico, metodológico o epistemológico ${ }^{33}$ ) de los que estemos hablando. En este empeño por mostrar la complementariedad de reducciónismo y emergentismo, resulta clarificadora la distinción que J. Searle hace de los reduccionismos, distinguiendo entre el eliminativista y el explicativo ${ }^{34}$. El eliminativista permite librarse de un fenómeno, mostrando que en realidad se trata de otra cosa. Es lo que ha sucedido a lo largo de la historia de la ciencia cuando un determinado concepto o fenómeno (como es el caso del flojisto, el gen, etc.) se ha explicado desde una base nueva de realidad, pudiéndose eliminar esos conceptos previos como superados e inservibles. En cambio, el reduccionismo explicativo es el que permite explicar o entender un fenómeno sin eliminarlo. Es el caso de mostrar o explicar la solidez de un

33 Cfr. Ayala, Fco. J. «Introducción», en Ayala, F.J./Dobzhansky, T. (eds.), Estudios sobre la filosofía de la biología, Barcelona, Tecnos, 1983, pp. 9-20.

34 Cfr. Searle, J., «Dos biólogos y un físico en busca del alma (Crick, Penrose y Edelman, pasados por la criba de la crítica filosófica)», Mundo Científico, 1996, nº 170, pp, 654-669; cfr. p. 660. 
objeto como consecuencia del comportamiento de las moléculas y átomos que la componen. Para J. Searle, este modo explicativo de las cualidades del nivel macromolecular desde el nivel micro es, en parte, la estrategia fundamental del emergentismo en filosofía de la mente.

Dentro del emergentismo también hay diferentes modos de entenderlo, como nos indica Philip Clayton en su libro Mind \& Emergence, from quantum to consciousness $^{35}$, distinguiendo entre el emergentismo fuerte y el débil. Mientras la emergencia fuerte defiende que la evolución ha ido originando nuevos niveles ontológicos de realidad, con sus leyes y fuerzas causales propias, la débil sostiene que sólo aparecen cualidades nuevas, manteniéndose los mismos procesos causales del nivel físico. Esta modalidad débil se opone al reduccionismo clásico, en la medida en que defiende que la emergencia es el resultado del proceso evolutivo que hace emerger propiedades nuevas impredecibles, aunque para esta postura se trata sólo de nuevos estadios y nuevas estructuras físicas. Esto es, no emerge una realidad nueva sino una mayor complejidad de la misma realidad físico-química. Algunos, como D. Dennett, denominan a este emergentismo emergencia inocente. Estaríamos, por tanto, ante una postura que defiende un monismo ontológico y un pluralismo de propiedades, como es el caso de M. Bunge en el ámbito de las relaciones mente-cuerpo ${ }^{36}$.

$\mathrm{Ph}$. Clayton es partidario del emergentismo en sentido fuerte, así como Paul Davies, autores que han compartido sus ideas sobre este punto en The re-emergence of emergence ${ }^{37}$. Tanto Clayton como Davies defienden que el emergentismo hay que entenderlo en el sentido fuerte, ontológico, puesto que la capacidad evolutiva de los sistemas físico-químicos permite hacer emerger propiedades nuevas que no son reducibles a las del nivel inferior, físico-químico o biológico, advirtiéndose que tales propiedades nuevas tienen efectos sobre los mismos sistemas físicos, o biológicos, que las han producido. De este modo, se da por hecho que la ciencia puede confeccionar experimentos comprobadores de esta relación causal entre los dos niveles de realidad, dejando de ser el paradigma emergentista una mera tesis filosófica, con tintes cuasi-religiosos, para convertirse en un planteamiento sometible a experimentación científica.

La tesis central del emergentismo es que la realidad está constituida por estructuras de todo tipo, en las cuales el todo es mayor que la mera suma de sus partes, poseyendo ese todo sistémico o estructural al menos una cualidad o propiedad que no la poseen ninguna de sus partes por separado. De ahí que los emergentistas distingan entre propiedades emergentes, (cualidades nuevas,

35 Oxford University Press, 2004. También hace esa clasificación David J. Chalmers, en The conscious mind: in search of a fundamental theory, N. York, Oxford University Pres, 1996.

36 Cfr. Bunge, M., El problema mente-cuerpo. Un enfoque psicobiológico, Madrid, Tecnos, 1985; Id., Epistemología, Barcelona, Airel, 1980; Id., Materialismo y ciencia, Barcelona, Ariel, 1981; Id., Racionalidad y realismo, Madrid, Alianza, 1985, cap. 9, «Explicaciones psicológicas», pp. 89-103.

37 2006. Hay una edición de 2008. Para una exposición amplia de las ideas de Ph. Clayton sobre el emergentismo, cfr. LEACH, J., o.c., pp. 1-7. 
propias del nuevo sistema o estructura emergido) y resultantes (propiedades de los elementos previas a la emergencia del nuevo nivel estructural).

Esta distinción entre el todo y las partes hace ver que al defender el emergentismo el hecho de que algo nuevo emerja, una nueva estructura o sistematización de la realidad, no se está diciendo simplemente que algo oculto emerge o se descubre en un momento determinado, sino que se produce una conformación ex novo de una nueva realidad u organización, constituyéndose esa nueva realidad en el mismo momento de su emergencia, sea cual sea la forma en que se entienda o explique tal emergencia o constitución. El paradigma emergentista consiste precisamente en defender la constitución de una realidad nueva, apoyada en un nivel previo de la realidad, surgiendo desde él y estando subtendida dinámicamente por él, según la concepción de Zubiri ${ }^{38}$. De tal modo que las dificultades e interrogantes que suscita el paradigma emergentista se refieren precisamente al modo de explicar cómo surge una realidad nueva y más compleja de otra distinta y menos compleja, qué relación hay entre los dos niveles de realidad, tanto en su origen como en su ser y actuar, y cómo conjugar la visión emergentista con la tendencia general reduccionista de la ciencia actual.

De todas formas, aunque la emergencia de estructuras novedosas es específica en cada ámbito de realidad en que se produce, todos los saltos emergentes poseen tres cualidades comunes: son saltos novedosos, impredecibles e irreductibles $^{39}$. En primer lugar, se trata de la emergencia de un nivel de realidad nuevo. Aunque no se trata de una novedad total y radical, ya que «las correspondientes (notas y propiedades) de los niveles evolutivos anteriores perduran en ella en subtensión dinámica ${ }^{40}$. Lo totalmente novedoso es la estructura o sistema que ha emergido ex novo, con sus correspondientes nuevas propiedades. Se trata, en segundo lugar, de un salto impredecible, "porque el más acabado conocimiento de la estructura evolutiva inmediatamente anterior, no permitiría adivinar su aparición ${ }^{41}$. Y, en tercer lugar, es irreductible a los niveles anteriores, tanto en su dimensión ontológica como epistemológica. De todos modos, no todos los emergentistas, como ya dijimos, aceptan la novedad ontológica, aunque sí la epistemológica. De ahí que indicáramos más arriba la diferencia entre un tipo de emergencia fuerte (admite novedad ontológica), frente a la novedad débil (admite sólo novedad epistemológica). La irreductibilidad epistemológica supone que el nuevo nivel emergido se rige por leyes nuevas, que da lugar a un tipo de saber específico, que no puede subsumirse o reducirse al saber del nivel anterior.

38 Cfr. ZubiRI, X., Estructura dinámica de la realidad, Madrid, Alianza/Fundación Xavier Zubiri, 1989.

39 Cfr. Ppoper, K. /Eccles, J., El yo y su cerebro, o.c.; Laín Entralgo, P., El problema almacuerpo, o.c., p. 27.

40 Laín Entralgo, P., El problema alma-cuerpo, o.c., p. 27.

41 Ibídem, p. 27. 
En definitiva, W. H. Thorpe, citando a Carl Pantin, considera que existen dos tipos de ciencias: las restringidas, entre las que estaría sobre todo la física, cuya característica es no parecer necesitar conceptos y métodos de otras ciencias, sino que se bastan con los correspondientes a la propia ciencia; y las ciencias no restringidas, las que necesitan continuar las explicaciones y descripciones de sus problemas en el campo de cualquier otra ciencia. En ese sentido, Thorpe observa que «existe una gran tendencia entre los biólogos a considerar este proceso de búsqueda de explicaciones físicas como la parte más importante de su trabajo, y por lo tanto a ser irresistiblemente reduccionistas en sus métodos y puntos de vista ${ }^{42}$. Siguiendo esta dinámica, la tendencia reduccionista en las ciencias se orienta a desmenuzar la realidad en sus diferentes partes, tratando de explicarlo todo en términos de átomos y partículas elementales. De ahí que la definición moderna de reduccionismo, como indica I. Barbour, sea el intento de «atribuir exclusivamente realidad a los constituyentes más pequeños del mundo, y la tendencia a interpretar niveles superiores de organización en términos de niveles inferiores ${ }^{43}$.

Los emergentistas consideran, en cambio, que la estrategia más acertada es conjugar los dos puntos de vista: una mirada analítica (que se orienta hacia la descomposición de una realidad en sus partes) y otra sintética (orientada a estudiar las características de las sistematizaciones o estructuras con que se va organizando la realidad). El error y la limitación que W. H. Thorpe advierte en la tendencia reduccionista exagerada, consiste en no darse cuenta de que todo proceso de análisis, aunque valioso y necesario, tiene que completarse siempre con el movimiento de síntesis. Por lo demás, el movimiento de análisis, propio del reduccionismo, es una abstracción, y, por tanto, una visión limitada, en la medida en que "es él mismo una abstracción de una realidad más compleja y elaborada, y, en este sentido, el término "ciencias restringidas" resulta adecuado ${ }^{44}$. De hecho, la misma física, como indicó ya B. Russel, necesita de las matemáticas para poder ser comprendida.

Pero la razón más convincente de Thorpe a favor de la necesidad de la síntesis es que nuestros sentidos perceptivos están diseñados para captar síntesis, sistemas, formas (Gestalten), estructuras. Y sólo después de que captamos totalidades, es cuando vamos hacia el análisis de esas estructuras para desentrañar los diferentes elementos o partes de las mismas. En consecuencia, «el análisis no sólo es engañoso, o aún peor, sin una síntesis previa; también carece de significado y es a veces extremadamente peligroso si no va seguido de síntesis, o por lo menos de períodos recurrentes de ella» ${ }^{45}$.

42 Thorpe, W. H., «El reduccionismo en la biología», en Ayala, F.J./Dobzhansky, T. (eds.), Estudios sobre la filosofía de la biología, Barcelona, Ariel, 1983, 152-187; p. 152.

43 Issues in Science and Religión, Londres, S. C. M. Press, 1966, p. 52 (cita tomada de W. H. Thorpe, o.c., p. 153).

44 Thorpe, W. H., o.c., p. 153.

45 Ibídem, p. 153. 
Desde una visión evolutiva de todo el universo, el modo más adecuado y completo de entender la realidad es, pues, analizarla desde una visión que conjugue complementariamente análisis y síntesis, necesitándose tanto el trabajo de descomposición de un todo en sus partes, como el de comprender las leyes específicas de los diferentes sistemas y estructuras que han ido emergiendo a lo largo del proceso dinámico y evolutivo. Nos topamos, pues, con el concepto y la idea de emergencia, que tiene que verse como complementaria a la visión analítica y reductiva. Thorpe, recurriendo a Broad, define emergencia como «la teoría de que el comportamiento característico del conjunto no podría, incluso teóricamente, deducirse del conocimiento más completo del comportamiento de sus componentes, tomados por separado o en otras combinaciones, y de sus proporciones y disposiciones en este conjunto ${ }^{46}$. Según este modo de ver las cosas, hay que distinguir en todo sistema o estructura dos niveles de realidad: la correspondiente a las partes y la del todo, necesitándose saber cómo se comportan las partes al margen del sistema, y bajo qué ley o leyes se han unido dichas partes para formar un sistema nuevo.

Siguiendo estos planteamientos, es evidente que las propuestas reduccionistas son inviables en muchos ámbitos de la realidad, entre los que se sitúa la biología respecto a la física, y el ámbito de lo mental respecto a la biología (neurociencias) o la física. En todos los ámbitos de las ciencias se han presentado teóricos que han advertido las insuficiencias del reduccionismo y la necesidad de los planteamientos emergentistas.

\subsection{Apuntes históricos y ámbitos del emergentismo.}

Aunque en la actualidad el emergentismo es un paradigma que se va aplicando a casi todos los ámbitos de la realidad, se utilizó por primera vez en el campo de la biología, para denominar, como indica J. Ferrater Mora, una teoría de la evolución: la teoría de la evolución emergente, propuesta por C. Lloyd Morgan, Samuel Alexander y otros ${ }^{47}$. Desde una concepción unitaria y dinámica de toda la realidad, en la que la vida brota de la materia y de ésta la conciencia, se entiende que "cada nivel del ser es emergente respecto al nivel anterior (e inferior)». Así, cada nivel es irreductible en su ser y en su actuar respecto al nivel anterior. Ahora bien, C. Lloyd Morgan reconoce que el concepto de emergencia ya lo había propuesto J. S. Mill en su Lógica, donde defendía que las leyes de la vida no pueden deducirse de las leyes de sus ingredientes o partes. La distinción a la que ya hemos hecho referencia anteriormente, entre

46 Broad, C. D., The Mind and its Place in Nature, Londres, Kegan Paul, Trench and Trubner, 1937 (cita tomada de W- H. Thorpe, o.c., p. 154. La cursiva es del autor).

47 Cfr. Ferrater Mora, J., Diccionario de Filosofía, Madrid, Alianza, 1980, 4 vols., vocablo Emergente, vol. 2, pp. 912-913; cfr. también Emergentismo, en Quintanilla, M. A. (dir.), Diccionario de filosofía contemporánea, Salamanca, Sígueme, 1976, p. 120; cfr. Emergencia, en Gregory, R. L. (ed.), Diccionario Oxford de la Mente, Madrid, Alianza, 1995, pp. 345-348. 
cualidades emergentes y resultantes, fue ya propuesta por C. Lloyd Morgan a sugerencia de G. H. Lewes.

Siguiendo a Matt Donnelley en su historia del paradigma emergentista en el ámbito anglosajón ${ }^{48}$, advertimos que ya el propio Darwin defendió de hecho el emergentismo, como consecuencia de su visión evolutiva del mundo de la vida, y tras él podemos considerar defensores del emergentismo en pleno siglo xIX a autores como Joseph Hooker (1871) y George Henri Lewes (1875). Y ya en el siglo xx, en paralelo al momento más álgido del vitalismo, se da un renacer del emergentismo de la mano de Samuel Alexander (1920), C. D. Broad (1925) y Stephen Peppere (1926). Y se puede considerar también cercano al emergentismo al gran filósofo A. N. Whitehead, con sus tesis sobre la filosofía del proceso, durante sus años de docencia en Harvard.

A lo largo de las décadas posteriores, se produjo un predominio de las posturas reduccionistas, considerándose al emergentismo como un planteamiento demasiado especulativo, cercano a posturas religiosas, y muy poco comprobable desde la óptica científica. Pero el emergentismo renacerá con fuerza en los años sesenta de la mano de filósofos como Ernest Nagel (1961) y P. W. Anderson (1972), y se consolidará con aportaciones de otros muchos más en la década de los ochenta y noventa, como es el caso de M. Silverstein, P. Humphreys, Tim O’Connor, R. Klee, Terry Deacon, Philyp Clayton, e incluso Stuart Kauffman, quien comenzó con una posición reduccionista que se puede perfectamente armonizar con la emergentista ${ }^{49}$. Pero esta lista se puede todavía ampliar haciendo referencia a diversos autores que defienden posturas emergentistas en el terreno de la filosofía de la mente, como Popper, Searle, M. Bunge, Edelmann, Damasio, etc. Y en el ámbito español, los filósofos Amor Ruibal y X. Zubiri han defendido posturas emergentistas, así como seguidores suyos en el terreno de la antropología médica, Barraquer Bordán, P. Laín Entralgo ${ }^{50}$ y Diego Gracia, así como el psicólogo José Luis Pinillos ${ }^{51}$.

Por otro lado, no hay hoy día ámbito científico donde no se vaya imponiendo el paradigma emergentista, desde la cosmología y la física, hasta la biología y la filosofía de la mente ${ }^{52}$. En el terreno de las matemáticas, de la física y de la

48 Cfr. Donnelley, M., en un artículo sobre el emergentismo, publicado en la revista Science \& Theology News, marzo 2006. Cita tomada de ARMengol, G., «El emergentismo, una vía humanista de la ciencia. Más allá del reduccionismo supera la imagen del hombre máquina», en http://tendencias 21.net/tendenciasdelasreligiones, 23-08-2007, pp. 1-4; 1.

49 Un panorama completo de la situación actual del emergentismo, en el ámbito anglosajón, se puede ver en CLAYTON, P./Davies, P., The Reemergence of Emergence, 2006. (cita tomada de Armengol, o.c., p. 3); CAPARrós, N./CRUz Roche, R. (dirs.), Viaje a la complejidad, 4 vols., Madrid, Biblioteca Nueva, 2012-2013.

50 Laín Entralgo, P., "El problema alma-cuerpo en el pensamiento actual», en MORA, Fco. (ed.), El problema cerebro-mente, Madrid, Alianza, 1995, pp. 17-35. 1991).

51 Cfr. Pinillos, J. L., La mente humana, Madrid, Salvat, 1969 (Madrid, Temas de Hoy,

52 Cfr. Beorlegui, C., «Los emergentismos sistémicos: un modelo fructífero para el problema mente-cuerpo», Pensamiento, 62(2006), n’ 234, 391-439; Id, "Emergentism», Pensamiento, 
química, el paradigma emergentista se ha ido imponiendo de la mano de las ciencias de la complejidad, que se ocupa del caos, de la teoría de las catástrofes, los fractales, y los autómatas celulares, entre otros fenómenos similares ${ }^{53}$. Uno de los defensores más significativos en el campo de la física es el Premio Nobel de física en 1989, R. B. Laughlin ${ }^{54}$, partidario de la complementariedad del enfoque reduccionista y el emergentista.

En el ámbito de la biología, cada vez son más los autores que se decantan por el paradigma emergentista como único modo de interpretar y explicar los rasgos propios de los seres vivos, así como su específico modo de comportarse. Aunque la biología no sabe resolver de momento todos los secretos y preguntas sobre el origen de la vida y el salto de la materia inorgánica a la vida, está claro que, aparte de advertir que la frontera es muy lábil, lo que caracteriza a la vida es una nueva y específica forma de organizarse la materia ${ }^{55}$. La primera célula eucariota se habría formado no a través de un proceso gradual, sino mediante un salto emergente, como consecuencia de un proceso de simbiosis de al menos tres elementos o formas de vida previa ${ }^{56}$. De este modo, puede advertirse que la materia biológica, aunque está conformada por la misma realidad atómica que estudia la física de partículas, representa un modo nuevo e imprevisible de organizarse, que implica, como indica Fco. J. Ayala, un tipo de comportamientos que pueden ser considerados como teleológicos o teleonómicos ${ }^{57}$, y que no pueden explicarse sólo desde el ámbito de las leyes físico-químicas.

También, y sobre todo, se ha afianzado el paradigma emergentista en el ámbito de la filosofía de la mente, como corriente explicativa de la emergencia de la conciencia, resultado de la complejificación de la estructura cerebral. Es en

o.c.

53 Cfr. Morin, E., Introducción al pensamiento complejo, Barcelona, Gedisa, 2008; Lewin, R., Complejidad. El caos como generador del orden, Barcelona, Tusquets, 1995/2002; GLEICK, J., Caos. La creación de la ciencia, Barcelona, Crítica, 2012; BaLAndier, G., El desorden. La teoría del caos y las ciencias sociales, Barcelona, Gedisa, 2003; WAGENSBERG, J., La rebelión de las formas, o cómo perseverar cuando la incertidumbre aprieta, Barcelona, Tusquets, 2004/2013; Mandelbrot, B. B., La geometría fractal de la naturaleza, Barcelona, Tusquets, 1997; CaparRo, N./Cruz Roche, R. (dirs.), Viaje a la complejidad, 4 vols., o.c.

54 Cfr. Lauglin, R. B., Un universo diferente. La reivindicación de la física en la era de la emergencia, Buenos Aires, Katz Editores, 2007.

55 Cfr. Margulis, L./SAgan, D., Microcosmos. Cuatro mil millones de años de evolución desde nuestros ancestros microbianos, Barcelona, Tusquets, 1995 (2013: $3^{\mathrm{a}}$ ed.); Kaufmann, S., Investigaciones. Complejidad, autoorganización y nuevas leyes para una biología general, Barcelona, Tusquets, 2003; Goodwin, B., Las manchas del leopardo. La evolución de la complejidad, Barcelona, Tusquets, 1998 (2008, 2a ed.); Luisi, P. L., La vida emergente. De los orígenes químicos a la biología sintética, Barcelona, Tusquets, 2010; Dyson, F., El infinito en todas direcciones, Barcelona, Tusquets, 1991.

56 Cfr. Margulis, L./SAGan, D., o.c., cap. 7 y 8; Dyson, F., o.c., cap. 4.

57 Cfr. Ayala, Fco. J., «Biology as an Autonomous Science», American Scientist, 1968, ${ }^{\circ}$ 56, pp. 207-221 (trad. cast., «La biología como una ciencia autónoma», en AyALA, F. J., La evolución de un evolucionista. Escritos seleccionados (Valencia, Universidad de Valencia, 2006), pp. 105-122; 111. 
este ámbito donde posiblemente se ha hecho más importante y visible este paradigma. El problema tradicional de las relaciones alma-cuerpo, estancado tras las estériles discusiones posteriores a Descartes y sus seguidores, rebrotó con fuerza a mitad del siglo pasado de la mano de la denominada nueva filosofía de la mente, consecuencia de la superación de la propuesta conductista y el rebrotar con fuerza de la recuperación de lo mental de la mano de varias propuestas filosóficas, entre las que destacan la teoría de la identidad, el funcionalismo y el emergentismo ${ }^{58}$.

Si para el conductismo no existe la mente, y para la teoría de la identidad la mente es simplemente el cerebro, para el funcionalismo la mente es un sistema de estados mentales que interactúan entre sí y con el entorno, distinguiendo entre la base material del cerebro (hardware) y el sistema o programa mental (software). Ahora bien, los intentos por parte del funcionalismo de superar el reduccionismo mental de la teoría de la identidad, no le evitaron desembocar en un cierto dualismo larvado, al separar de tal modo la mente de su apoyo cerebral, que éste queda totalmente postergado. En cambio, para el emergentismo, el cerebro, y el cuerpo humano, sí importan, puesto que la mente es la específica estructuración del cerebro, como consecuencia del largo proceso evolutivo que ha experimentado desde la etapa del denominado cerebro reptiliano, pasando por el cerebro de los mamíferos, hasta llegar al del homo sapiens. Por eso, lo específico del emergentismo en este campo consiste en afirmar que la mente ha emergido o surgido de la evolución del cerebro. En definitiva, el cerebro sí importa a la hora de tener un concepto de lo mental. Así, para esta postura, la mente es el sistema o la estructura específica con la que está configurado nuestro cerebro, fruto del largo proceso de evolución biológica a través del cual se ha conformado. Ahora bien, el problema de esta teoría es que se puede defender esto y no coincidir después en qué idea se tenga de esa estructura mental, ni tampoco con la ontología o antropología que se tenga de fondo.

Para definirlo de un modo adecuado, al emergentismo hay que adjetivarlo como estructurista o sistemista; es decir, afirmar que la mente es el sistema o estructura específica emergida en la evolución, y esa especial estructuración o complejidad de lo cerebral es lo que le permite a la mente humana poseer sus especiales características, e interactuar sobre la base neuronal del cerebro para dirigir la conducta.

58 Cfr. Gardner, J., La nueva ciencia de la mente. Historia de la revolución cognitiva, Barcelona, Paidós, 1987; Churchland, P. M., Materia y conciencia. Introducción contemporánea a la filosofía de la mente, Barcelona, Gedisa, 1999; MArTínez-Freire, P. F., La nueva filosofía de la mente, Barcelona, Gedisa, 1995; Liz, M., Perspectivas actuales en filosofía de la mente, Tenerife, Gobierno de Canarias, 2001; Hierro-Pescador, J., Filosofía de la mente y de la Ciencia cognitiva, Madrid, Akal, 2005; Moya, C. J., Filosofía de la mente, Valencia, PUV, 2004; BeorLEGUI, C., «Filosofía de la mente. Visión panorámica y situación actual», Realidad (UCA, San Salvador), 2007, $\mathrm{n}^{\circ}$ 111, enero-marzo, 121-160. 
4. Elementos esenciales del emergentismo de J. Monserrat

Javier Monserrat es uno de los autores que más se ha esforzado en explicitar y construir sistemáticamente el paradigma emergentista, teniendo en cuenta tanto los últimos datos de las ciencias del cerebro y de las diferentes ciencias cognitivas, como la reflexión filosófica desde la que hacer coherente el punto de vista emergentista. Sus reflexiones han ido evolucionando desde una primera presentación clasificadora de las diferentes posturas dentro de la filosofía de la mente, situándose él en la emergentista, hasta posteriormente orientar su foco reflexivo hacia las tesis más convincentes sobre la emergencia de la conciencia a partir de la complejificación del cerebro, de la mano de autores que sitúan el despertar de la conciencia como consecuencia de fenómenos cuánticos en el interior de la neuronas.

\subsection{El monismo emergentista humanista.}

Podemos decir que Monserrat llega al interés por las posturas diversas sobre la naturaleza de la mente, para situarse dentro del emergentismo, desde la epistemología, la psicología cognitiva y de la ciencia de la visión, esto es, desde el interés por descubrir los mecanismos del conocimiento humano. A la hora de explicar dicho conocimiento, es lógico que nos hagamos también cuestión sobre el sujeto de ese conocimiento: la mente o la conciencia. Este acercamiento a una teoría de la mente desde el enfoque epistemológico, se halla presente en dos de sus primeros libros: Epistemología evolutiva y teoría de la ciencia, y La percepción visual.

En ambos libros, dedica amplios capítulos a presentar el mapa de las principales teorías sobre la mente y las relaciones con el cuerpo o el cerebro, situándose él mismo, dentro de ese panorama, como emergentista ${ }^{59}$, y definiendo su postura como emergentismo humanista, o mejor, monismo emergentista humanista ${ }^{60}$. Es importante atender a cada una de los tres términos para dar fiel cuenta de su postura, como iremos viendo.

Monserrat presenta el amplio abanico de posturas sobre la mente y el problema mente-cuerpo con objeto de resaltar mejor el perfil de su emergentis$\mathrm{mo}^{61}$, que define, de entrada, como una teoría hipotética, esto es, como un macroconstructo explicativo hipotético ${ }^{62}$. En el empeño por explicar cómo se produce el conocimiento humano, en el primer libro (Epistemología...) Monserrat va mostrando la estructura de los diversos momentos epistemológicos

59 Cfr. Monserrat, J., Epistemología Evolutiva y Teoría de la Ciencia, Madrid, UPCO, 1987, sobre todo el cap. VI; Id., La percepción Visual. La arquitectura del psiquismo desde el enfoque de la percepción visual, Biblioteca Nueva, Madrid, 1998, XIV, segunda edición ampliada en 2008.

60 Epistemología Evolutiva.., o.c., p. 170.

${ }^{61}$ Cfr. Epistemología evolutiva..., o.c., cap. VI, p. 179 y ss.; Id., «Engramas neuronales y teoría de la mente», o.c., p. 179.

${ }^{62}$ Cfr. Epistemología evolutiva, o.c., p. 161. 
que se advierten en el hecho de conocer la realidad, para estudiar con amplitud y profundidad en el segundo (La percepción visual) los procesos de la visión humana, y desde ahí llegar a la mente, como centro unificador de todos los procesos sensoriales y cognitivos.

a) Monismo...

Monserrat considera que todas las posturas se pueden reducir, dejando de lado el dualismo («una posición marginal»), a dos: el paradigma mecanicista-formalista-computacional y el paradigma funcional-evolutivo-emergentista, convencido de que es este segundo paradigma el que se halla más de acuerdo con los avances de las ciencias del cerebro y el que soluciona de forma más convincente las deficiencias de las demás teorías de la mente. El paradigma que denomina mecanicista-formalista-computacional no logra dar cuenta de «la experiencia fenomenológica de nuestra actividad psíquica» ${ }^{63}$, es decir, las experiencias subjetivas de la conciencia, así como tampoco explican de forma adecuada el funcionamiento del cerebro, reduciéndolo a su nivel puramente físico y mecanicista, dando la espalda a su nivel estructural y sistémico. Frente a esa visión mecanicista y computacional (la mente es un programa formal, obviándose la experiencia interna subjetiva), Monserrat propone el modelo evolutivo-funcional-emergentista.

Los puntos centrales de este planteamiento consisten en situar el problema de la mente dentro de una visión dinámica del mundo, que se completa con la evolución de las diversas especies vivas, y se corona con la emergencia de lo mental en las especies animales superiores y la mente autoconsciente en la especie humana. La mente humana se entiende como el sistema global con que está configurado el cerebro humano, que le permite ser y actuar con las características específicas de lo humano, y que la dotan de una densidad ontológica y ética específica, base adecuada para apoyar y defender su postura humanista. Por tanto, la mente humana sería «aquel conjunto sistémico de recursos físicos, biológico-neurológicos y psíquicos que sustentan en el organismo viviente humano los procesos de detección de información y elaboración de respuestas adaptativas al medio en la forma específicamente humana ${ }^{64}$.

La física actual nos ha mostrado que la materia se descompone, en último término, en energía, estableciéndose entre ambos conceptos la relación prescrita por la célebre fórmula de Einstein $(\mathrm{E}=\mathrm{mc} 2)$ de la teoría de la relatividad restringida. Esto nos hace ver que la ciencia física actual no tiene ya una definición fija y acabada de materia, sino que ésta, nos dice Monserrat, es "todavía un "black box" u "objeto negro" cuya íntima estructura está todavía por desentrañar últimamente. La realidad física es aun hoy para la ciencia un enigma o cuestión abierta»65.

63 «Engramas neuronales y teoría de la mente», Pensamiento, 57 (2001), n 218, pp. 177$211 ; 180$.

${ }^{64}$ Ibidem, p. 178.

65 Epistemología evolutiva ..., o.c., p. 164; cfr. Id., Hacia el nuevo Concilio. El paradigma de la modernidad en la Era de la Ciencia, Madrid, San Pablo, 2010, pp. 232 y ss. 
La concepción dinámica del universo nos permite afirmar que la realidad está en permanente transformación y estructuración, uno de cuyos principales momentos es el salto o emergencia de la materia no viva a la vida. Las realidades biológicas emergidas nos muestran las características propias del mundo de la vida: «movimiento, crecimiento, nacimiento y muerte, desarrollo organizado en pertenencia a la especie, asimilación de substancias provenientes del medio, unidad funcional, reproducción, autocontrol, espontaneidad reactiva frente a las estimulaciones del medio, adaptabilidad, etc. $»^{66}$.

Aunque situado entre el dualismo y los monismos fisicalistas, el emergentismo que defiende Monserrat se considera monista, pero un monismo abierto, es decir entiende que «el principio único de lo real evoluciona en un proceso continuo en que cada uno de los estados que adquieren los seres físicos en el universo es una derivación de estados anteriores ${ }^{67}$. Por tanto, la mente es una realidad diferente a la mera suma de neuronas, pero una realidad objetiva que interactúa con el cerebro y con el conjunto del cuerpo. Ya hemos señalado que el modo de explicación concreta del modo como se produce la causación de la mente desde y sobre la base material del cerebro está lejos aún de ser entendida y explicada del todo por los científicos del cerebro. Y quizás, aunque se llegara a desentrañar todos los entresijos del funcionamiento cerebral, es posible que la cuestión radical siga quedando a oscuras. De ahí que indique Monserrat que la postura más extendida entre los neurofisiólogos sea la denominada agnosticismo psicofísico interaccionista ${ }^{68}$. Se trata no sólo de una reserva lógica ante la situación de ignorancia de las investigaciones, sino de una postura consecuente con la limitación epistemológica del saber científico. Pero, no obstante, se pueden plantear hipótesis que vayan más allá de las evidencias empíricas y que guíen sus investigaciones. Y eso es lo que hace la hipótesis emergentista.

b) ... emergentista...

A la hora de explicitar en qué consiste esta tesis emergentista, Monserrat sigue los planteamientos clásicos del emergentismo: la conciencia es el resultado de una nueva y específica organización de la materia biológica. Por tanto, no es una producción de una realidad distinta de la materia, como afirma el dualismo. En cambio, «lo que se produce o emerge es simplemente una nueva organización sistémica o estructural de la materia ${ }^{69}$. Además, la emergencia de la conciencia hay que situarla en una serie continua de emergencias en el proceso evolutivo. La vida ha ido experimentando diferentes procesos emergentes, como consecuencia de nuevas e imprevisibles estructuraciones, que originan diversas formas de ser y de comportarse. Así, unos sistemas emergentes se apoyan en los anteriores, y dan lugar a otros posteriores. Hay, pues, continuidad y ruptura. Si de la materia no viva ha emergido la vida, y, dentro de ella,

66 Ibídem, p. 165.

67 Ibidem, p. 181.

68 Cfr. Ibídem, pp. 182-183.

69 Ibídem, p. 171. 
sus múltiples formas, de la materia biológica ha emergido la conciencia, como resultado de la complejificación del cerebro y con capacidad de hacerse cargo de sí misma.

Ante la cuestión inevitable, y todavía no resuelta, de cómo es posible que desde la materia biológica haya emergido una realidad que es capaz de introspección y con capacidad de unir e integrar la totalidad del organismo y sus acciones, entiende Monserrat que la postura emergentista resulta ser una hipótesis más convincente que el dualismo y el monismo reduccionista ${ }^{70}$. La conciencia es consecuencia de una nueva sistematización de la realidad biológica, cerebral, y no consiste en una realidad diferente, de tipo espiritual, que haya sido introyectada en algún momento en el organismo humano. El análisis de la actividad de la conciencia no muestra una actividad separada del cerebro y del cuerpo humano, de tal forma que se ve claro que «el proceso de la conciencia no se produce sin el soporte causal de los mecanismos sistémicos que la posibilitan ${ }^{71}$. La base material biológica, posibilita la emergencia de la conciencia por el modo como se halla sistematizada y estructurada, de tal modo que es capaz de poseer un núcleo integrador de la auto-experiencia, el sujeto activo, el yo. La autoconciencia humana es una nueva y más compleja sistematización de la conciencia animal, de tal modo que esa conciencia es ahora capaz de ser un yo o sujeto activo, centro unificador de sus diferentes experiencias tanto sensoriales como intelectuales, así como fuente de acciones creativas y libres.

El paradigma evolucionista da por hecho que la conciencia y la autoconciencia han representado una ventaja indudable en la lucha por la supervivencia. La autoconciencia es una ventaja a la hora de advertir los estímulos que se nos presentan, así como a seleccionar las respuestas que tenemos que dar. «La aparición de la conciencia, por tanto, debe entenderse como un factor de perfeccionamiento en el proyecto teleonómico de supervivencia en que parecen consistir los seres vivos ${ }^{72}$. De este modo, todo apunta a que la orientación del proceso evolutivo se ha ido orientando hacia la funcionalidad de la conciencia, convirtiéndose ella en la pieza clave que corona la conducta de los organismos vivos, lo que supone aceptar la hipótesis de la sensibilidad de la materia ${ }^{73}$. La materia es capaz de sentir el resto de la realidad que la envuelve, hasta llegar al nivel de la conciencia, como capacidad de sentir y de darse cuenta de sí misma, resultado de una nueva y compleja sistematización de la materia biológica, que alcanza una nueva sensibilidad, una sensibilidad propia del sistema.

Esta hipótesis o propuesta emergentista conlleva una ventaja indudable respecto a las muchas otras hipótesis que se han dado a lo largo de la historia del pensamiento, tanto en relación a la naturaleza de la conciencia como a los intentos de resolver el denominado problema psicofísico, las relaciones

70 Cfr. Ibídem, pp. 171-172.

71 Ibidem, p. 173.

72 Ibidem, p. 175.

73 Cfr. Ibídem, p. 176. 
alma-cuerpo o mente-cuerpo. Monserrat se extiende en presentar, tanto en Epistemología evolutiva como en La percepción visual, el amplio abanico de teorías que han intentado explicar la conciencia y su relación con el cerebro y el cuerpo ${ }^{74}$.

A la hora de enfrentarnos a la descripción de la mente, nos encontramos con el problema de la necesidad de utilizar dos vías alternativas de acceso: el objetivo y el subjetivo o introspectivo. Ninguna de las dos vías por separado es capaz de dar cumplida definición de la mente autoconsciente. La vía objetiva es la que ha seguido la moderna filosofía de la mente propia del ámbito cultural anglosajón, desde el conductismo a los monismos fisicalistas e incluso el funcionalismo computacional. La limitación más importante a esta vía de acceso consiste en no poder nunca dar cuenta de las experiencias subjetivas e interiores. La vía introspectiva ha sido la propia de la filosofía europea tradicional, desde los griegos hasta la fenomenología y el psicoanálisis. Pero su limitación está en no poder escapar a una idea de lo mental que no podrá ser contrastada en un ámbito interpersonal y objetivo.

Sólo podrá ser, por tanto, aceptable una teoría de la mente que pueda dar cuenta de ambas dimensiones, objetiva e interior, y ese es el reto y el acierto de la tesis emergentista. El emergentismo está de acuerdo con la teoría de la identidad y demás monismos fisicalistas a la hora de afirmar la centralidad del cerebro en el momento de explicar lo mental, pero discrepa de su pretensión de reducir lo mental al mero funcionamiento físico, neuronal, del cerebro. Está también de acuerdo con el funcionalismo computacional en no reducir lo mental al funcionamiento físico del cerebro, distinguiendo entre la base material cerebral y la funcionalidad de lo mental. Pero discrepa de esta postura en el modo como entienden la relación entre la mente y el cerebro, según la metáfora del ordenador. Si para el funcionalismo la base material (hardware) no es determinante de cara a la programación (software), para el mergentismo la base material de lo mental (en este caso, la realidad biológica del cerebro) sí importa, porque sólo un cerebro como el del ser humano es capaz de poseer una mente autoconsciente. Por ello, la propuesta del modelo emergentista consiste en entender la mente como el especial modo de estar estructurado el cerebro humano, estructuración producida y emergida en el proceso evolutivo.

Este modo de ver las cosas parece sencillo, pero no deja de presentar un serio problema, como bien nos hace observar Monserrat. Visto desde la óptica objetiva y científica, la diferencia entre el cerebro humano y el de la especie viva anterior no deja de ser una nueva aglomeración muy numerosa de neuronas interconexionadas. Pero, «¿cómo es posible que una estructura físico biológica que puede descomponerse en partes, que se interrelacionan entre ellas a través de fenómenos físicos químico-eléctricos, pueda producir la experiencia introspectiva de conciencia, con la sensación de penetración unitaria e integración

74 Cfr. Epistemología evolutiva, o.c., pp. 179- 201; La percepción visual, pp. 543-553. 
de la totalidad del organismo?» ${ }^{75}$. Tal efecto es producido, según la hipótesis emergentista, por el sistema total del cerebro. Pero tal afirmación no pasa de ser una mera hipótesis explicativa, que las ciencias del cerebro tratan en la actualidad de mostrar y explicar, y que el propio Monserrat nos indica a través de la teoría de las «engramas neuronales», como veremos más adelante.

De todos modos, el postulado emergentista se apoya, en opinión de Monserrat, en tres razones importantes: «a) es la hipótesis más obvia en el proceso de explicación unitario de la realidad; b) es una hipótesis intrínsecamente posible, aunque oscura (...), perfectamente coherente con los datos de la experiencia; c) es una hipótesis que crea menos problemas explicativos y oscuridades que las hipótesis alternativas que pueden proponerse (principalmente la dualista) para explicar el problema del origen de la conciencia» ${ }^{76}$.

La conciencia así emergida es, para la tesis emergentista, «resultado de un estado sistémico», "una cualidad interna de una organización sistémica específica de la materia ${ }^{77}$. Como en todo proceso emergente, se da continuidad material con el nivel anterior, al mismo tiempo que una sistematización original que dota a esa nueva estructura de capacidades también nuevas (pensamiento, conciencia, libertad, etc.). Ahora bien, esto no significa, como ya lo hemos dicho, entender la realidad de la conciencia como algo separado e independiente del funcionamiento del cerebro (es la tesis dualista). "La experiencia introspectiva de la conciencia, (...), no presenta indicios suficientes de una actividad separada. Además, parece más obvio pensar que si la conciencia se genera por un estado sistémico, los procesos reales de conciencia dependerán del soporte continuo de los mecanismos sistémicos que la producen». Dicho brevemente: «el proceso de conciencia no se produce sin el soporte causal de los mecanismos sistémicos que la posibilitan ${ }^{78}$.

Así, aunque las investigaciones sobre el cerebro no nos permiten todavía conocer más que algunos mecanismos del proceso de la conciencia, sí parece que nos permiten decir al menos dos cosas: «el principio o causa del hecho de la conciencia es un estado sistémico de la materia», y «el principio o causa de los procesos de conciencia son los mecanismos sistémicos que permiten constituir puntualmente y mantener distendido en el tiempo el estado de conciencia» ${ }^{79}$. Todo el sistema tiene que funcionar de modo coordinado e interdependiente, de modo que «si fallaran los aspectos más simples del mecanismo sistémico no habría ni conciencia ni proceso consciente» ${ }^{80}$.

El modelo emergentista nos permite afirmar que esta nueva sistematización del cerebro es la causa de la experiencia subjetiva de la conciencia y la existencia de ese sujeto unificador de la conducta y de los procesos mentales

75 Ibídem, p. 172.

76 Ibidem, pp. 172-173.

77 Ibídem, p. 173.

78 Ibídem, p. 173.

79 Ibídem, p. 173.

80 Ibídem, p. 174. 
que denominamos el «yo». «La hipótesis emergentista, fundamentada en la experiencia introspectiva, postula que el mecanismo sistémico principia o causa a) la conversión de la conciencia en conciencia de un sujeto activo o yo, b) la orientación de los procesos conscientes a contribuir a la actividad de ese yo, y c) la inclinación o toma de decisión con que el yo orienta su conducta de una u otra manera para adaptarse al medio en la supervivencia» ${ }^{81}$. Consecuente con lo dicho más arriba, la actividad del yo no supone una actividad separada de su soporte cerebral, sino que está causada por el mecanismo sistémico. La existencia de ese yo que unifica los actos de conciencia y orienta su relación con el medio se presenta como una realidad necesaria para la supervivencia de cada ser humano, por lo que parece obvio que la complejidad de la vida humana exige estar coronada por un sujeto activo, un yo. De este sujeto activo hay que decir, en primer lugar, que ha supuesto claramente una ventaja evolutiva para los seres vivos que lo poseen o constituyen, puesto que pueden de este modo controlar de forma más eficaz todo tipo de información que les llega del entorno, así como responder a esos estímulos de la forma más eficaz. En realidad, "la constitución de la conciencia como "sujeto activo" no parece otra cosa que la "conciencia" de esa función controladora de la información y seleccionadora y controladora de respuestas, tal como es ejercida por la conciencia» ${ }^{82}$.

Este yo es de naturaleza plástica, en la medida en que es activo y no sólo controla la información del entorno, material e interpersonal, sino que es autoconsciente de sí mismo e influye sobre la propia conducta, sobre «los mismos mecanismos sistémicos que producen la conciencia». Así, pues, «este bucle causal representa el modo de interconexión entre el hecho real de la conciencia y el hecho de los mecanismos sistémicos que la producen ${ }^{83}$.

La explicación de la posibilidad de esta emergencia de la conciencia y del yo como sujeto activo que unifica los procesos mentales y conductuales está, para la tesis emergentista, en «la funcionalidad biológica de la conciencia en orden al proyecto teleonómico de supervivencia de los organismos» ${ }^{84}$. Si comparamos la forma de reaccionar ante los estímulos del entorno de un ser vivo puramente mecánico y otro dotado de conciencia, se advierte enseguida la clarísima ventaja adaptativa de la conciencia frente a su carencia. Esto nos hace ver que la orientación teleonómica del proceso evolutivo ha estado apuntando a la emergencia de la conciencia como algo lógico, y sólo con la coronación de la unificación de la conciencia o del yo ha podido sobrevivir un ser vivo como el ser humano. Porque «si de un organismo superior consciente suprimiéramos la conciencia, el ochenta por ciento de su programación sistémica carecería de sentido y con el veinte por ciento restante no podría sobrevivir ${ }^{85}$. Así, pues, todo el proceso evolutivo parece orientado hacia la emergencia de «la

$81 \quad$ Ibidem, p. 174.

82 Ibídem, p. 174, nota 9.

83 Ibídem, p. 175.

84 Ibídem, p. 175.

85 Ibidem, p. 175. 
funcionalidad de la conciencia como pieza clave del proyecto teleonómico de supervivencia» ${ }^{86}$. Con esta referencia al fenómeno de la supervivencia Monserrat no quiere defender una noción antropológica puramente biologista, como si la única finalidad de la existencia humana fuera sobrevivir, sino que el sobrevivir es la base y la condición de posibilidad del resto de las demás finalidades mentales y culturales del ser humano.

c) ... humanista.

A la hora de preguntarse por el origen de la conciencia, Monserrat advierte que se dan dos posturas fundamentales enfrentadas: el monismo y el dualismo, situándose él en «una forma de monismo que llamamos emergentismo humanista, por cuanto creemos que se trata de un emergentismo que permite dar razón - lo que no puede decirse sin más de todos los emergentismos- de la dignidad del hombre como sujeto activo, responsable y creador libre de su conducta» ${ }^{87}$.

El ser humano es una realidad biológica más dentro del amplio mundo de la biosfera, en la medida en que está constituido por el mismo material biológico y sometido a sus mismas leyes de funcionamiento y reproducción. Pero dentro de su semejanza con el resto de la biosfera, también se da en el ser humano una específica originalidad, constituida sobre todo por su dotación mental. Así, en el ser humano se da una continuidad con la realidad física y biológica, al mismo tiempo que una ruptura cualitativa, constituida sobre todo por su mente autoconsiente. El ser humano es, pues, como el resto de los demás seres vivos, «materia organizada biológicamente» ${ }^{88}$.

La base material biológica, posibilita la emergencia de la conciencia por el modo como se halla sistematizada y estructurada, de tal modo que es capaz de poseer un núcleo integrador de la autoexperiencia, el sujeto activo, el yo. La autoconciencia humana es una nueva y más compleja sistematización de la conciencia animal, de tal modo que esa conciencia es ahora capaz de ser un yo o sujeto activo, centro unificador de sus diferentes experiencias tanto sensoriales como intelectuales, así como fuente de acciones creativas y libres.

Monserrat entiende que el proceso de emergencia hay que entenderlo como un postulado, o una hipótesis ${ }^{89}$, esto es, como una propuesta teórica no demostrada ni demostrable en todos sus términos. Y esa hipótesis propone que «la conciencia emerge de determinadas formas de organización biológica de la materia en el modo en que nos obligan a entender los datos de la

\footnotetext{
86 Ibídem, p. 175.

87 Ibídem, p. 170. Las cursivas son del autor.

$88 \quad$ Ibidem, p. 167.

89 «Postulado, indica Monserrat, es una suposición que no puede ser probada, pero que se establece para dotar de coherencia fundamental un sistema de enunciados; hipótesis es una suposición que se establece para solucionar un determinado problema y que puede ser confrontada con los datos de la experiencia, aspirando en algún sentido a lograr así contrastación empírica»: Ibídem, p. 172, nota 7.
} 
experiencia $»^{90}$. Ahora bien, «emergencia no significa producción de una realidad nueva distinta de la materia, aunque originada por ella. Lo que se produce o emerge es simplemente una nueva organización sistémica o estructural de la materia ${ }^{91}$. Por tanto, no se produce realidad material nueva, sino una nueva organización o sistematización de la realidad. Pero «la emergencia de nuevos estados sistémicos puede producir la aparición de "modos de ser real, físico y biológico distintos", posibilitados por las nuevas cualidades de esos estados sistémicos $»^{92}$.

En todo proceso de emergencia de una realidad nueva, hay que tener en cuenta dos elementos complementarios: una continuidad y una ruptura o salto cualitativo. Se da continuidad: lo nuevo ha surgido de lo que ya había, y está hecho de la misma realidad material; pero también se da una ruptura cualitativa, en la medida en que se produce una nueva sistematización, una nueva realidad, con propiedades y características nuevas. Así, un ser vivo está hecho de los mismos componentes físicos que un ser no vivo, pero representa una realidad cualitativamente nueva, puesto que está configurada por una nueva sistematización de lo físico, dotada de un modo de ser y de actuar totalmente diferente. Y lo mismo ocurre con la emergencia de lo mental desde lo biológico, como último eslabón de todo el proceso evolutivo.

\subsection{De los engramas neuronales a la neurología cuántica.}

Dentro del paradigma emergentista, y ciñéndonos ya al ámbito de la emergencia de la conciencia, las propuestas son muy diversas. Monserrat ha ido pasando de situar la solución a la emergencia de la mente en el ámbito de los engramas neuronales, a defender con fuerza y seguridad la línea de la neurología cuántica, propuesta por varios autores, entre los que destacan Penrose y Hameroff. De todos modos, no se trata de dos propuestas contrarias, sino complementarias, como vamos a ver.

\subsubsection{Los engramas neuronales.}

Dentro de la propuesta emergentista, como modelo de relación mentecuerpo, hay, como ya hemos dicho, una amplia pluralidad de propuestas y de posturas. Monserrat se ha detenido en varios de sus escritos en la descripción y valoración crítica de los más importantes emergentistas. En Epistemología evolutiva, ha presentado con amplitud las teorías de Sperry (emergentismo autonomista), M. Bunge (emergentismo psicobiológico), y K. R. Popper (emergentismo autonomista aporético $)^{93}$, exponiéndolas y desmarcándose críticamente de cada uno de ellos. Igualmente, ha dedicado diversos artículos a estudiar

$90 \quad$ Ibidem, p. 171.

91 Ibidem, p. 171.

92 Ibídem, p. 171. Las comillas son del autor.

93 Cfr. Epistemología evolutiva, o.c., pp. 193-199. 
críticamente las propuestas de Fr. Crick ${ }^{94}$, J. Searle ${ }^{95}$, Damasio ${ }^{96}$ y Edelmann ${ }^{97}$. Todos estos autores, de diferente forma, coinciden en el empeño de explicar la emergencia de la mente o de la conciencia desde la óptica de la complejificación estructural del cerebro. La gran cuestión, como sabemos, que se plantea a la hora de explicar la emergencia de la conciencia es cómo explicar que los procesos bioquímicos del cerebro den lugar a las actividades psicológicas de la conciencia. La explicación estándar del emergentismo se orienta a explicar la mente como resultado de la extraordinaria complejidad de la sistematización del cerebro humano, fruto del proceso evolutivo. Es la línea que siguen Searle, Edelmann, Damasio y otros emergentistas, con mayor o menor acierto y explicitación. Pero esta tesis no pasa de ser un simple modelo explicativo, que no muestra cómo esa compleja sistematización cerebral da lugar a la aparición de la conciencia.

La teoría de los engramas neuronales, que defiende Monserrat en algunos de sus escritos ${ }^{98}$, recoge los aspectos más interesantes de esta orientación emergentista. La causación entre la mente y el cuerpo se entiende en el emergentismo tanto en sentido ascendente (del cerebro o sistema nervioso central a la mente) como descendente (de la mente al cerebro y al cuerpo entero). Por tanto, la mente es una realidad determinada (por el cerebro) y determinante (es la causa y el sujeto de los estados mentales y conductuales). El cerebro, como sabemos, está conformado por millones de neuronas, que se van uniendo y entrelazando entre sí (sinapsis) para formar redes relacionales denominadas engramas neuronales ${ }^{99}$, aunque también han recibido otras denominaciones como bucle neuronal, estructura neuronal, o subsistema neuronal ${ }^{100}$. Unos son innatos, nacemos dotados de ellos para poder realizar los comportamientos necesarios que nos permiten sobrevivir nada más nacer, y otros se van conformando como consecuencia de nuestra interacción con el entorno material e interhumano ${ }^{101}$. Los engramas producen acumulación de experiencia, siendo razonable pensar que son los elementos cerebrales donde se sitúan los qualia, las experiencias subjetivas. Si no son engramas aislados, sí acumulación de

94 «Francis Crick y la emergencia de la conciencia visual», o. c.

95 «John Searle en la discusión sobre la conciencia», o.c.

96 «Teoría de la mente en Antonio Damasio», o.c.

97 «Gerald M. Edelman y su antropología neurológica: Presentación y discusión de su teoría de la mente», o. c.

98 Cfr. «Engramas neuronales y teoría de la mente», o.c.; Ibídem, Hacia el nuevo Concilio, o.c., pp. 251 y ss.

99 «Engrama, define Monserrat, es una estructura de interconexión neuronal en el cerebro producida por la propagación terminal de los impulsos nerviosos químico-eléctricos (transmitidos por vía sináptica) originados en las terminaciones del S. N. Conectadas con el medio interno o externo»: «Engramas neuronales y teoría de la mente», o.c., p. 186.

100 Cfr. «Engramas neuronales y teoría de la mente», o.c., p. 185.

101 Cfr. Ibidem, pp. 198-199. 
engramas interconexionados, convirtiéndose «en soporte neuronal de los engramas finales productores de conciencia» ${ }^{102}$.

De todas formas, todavía desconocemos lo fundamental del funcionamiento del cerebro, siendo lo más importante el resolver la cuestión de cómo y «por qué el psiquismo emerge de las estructuras neuronales» ${ }^{103}$. De momento sabemos que la conciencia tiene que ver y está relacionada con las interrelaciones entre las neuronas, los engramas, pero no sabemos todavía cómo sucede eso y por qué la experiencia cualitativa emerge de ahí. Monserrat estudia la formación de estos engramas en relación con el sentido de la vista, siguiendo los últimos avances de la ciencia de la visión ${ }^{104}$. Algunas células del organismo se hacen sensibles a la luz, produciendo en ellas una transformación químicoeléctrica que dispara un impulso nervioso que se transmite a lo largo del axón neuronal. "La forma más obvia de terminar el impulso que se transmite es quedar encerrado en un bucle neuronal: una estructura de neuronas, aunque sea muy simple, cuatro o cinco neuronas (o células que transmiten ese tipo de impulso nervioso), en la que queda encerrado; es decir, reflejándose de una neurona a otro en un bucle cerrado» ${ }^{105}$.

Estos bucles neuronales se van especializando en recibir determinadas impresiones, y responder de una forma determinada a los estímulos, al mismo tiempo que se van formando bucles y engramas más complejos, para generar relaciones de estímulo-respuesta más complicados. Resulta interesante en este punto la propuesta de darwinismo neuronal de Edelmann, que Monserrat valora críticamente en uno de sus trabajos ya citados $^{106}$. El cerebro humano va conformando estos bucles y engramas durante el tiempo de su gestación intrauterina, para seguir tras el nacimiento en un proceso complejo y sin pausa de formación de estructuras, bucles neuronales, desechando otras propuestas por no ser tan necesarias ni valiosas. De este modo, «los bucles terminales de estas estimulaciones nerviosas, inicialmente lineales, van complejizándose y concentrándose en lugares del organismo, hasta producir redes neuronales $\mathrm{y}$, por último, el cerebro como elemento fundamental de un S. N. (sistema nervioso) central» ${ }^{107}$.

Este tipo de estructuras neuronales se ha denominado de diferentes formas según los diversos autores que investigan el proceso evolutivo de la formación del sistema nervioso y el cerebro. De este modo, Monserrat advierte que "puede hablarse de patrón de activación, de bucle neuronal, de estructura neuronal, de subsistema neuronal, o de "engrama neuronal", entre otras denominaciones también comunes» ${ }^{108}$. Pero, por encima de las diferentes de-

\footnotetext{
102 Ibídem, p. 189.

103 Ibídem, p. 190.

104 Cfr. El proceso visual, o.c.,

105 «Engramas neuronales y teoría de la mente», o.c., p. 182.

106 Cfr. nota 95.

107 «Engramas neuronales...», o.c., p. 183.

108 Ibídem, p. 185.
} 
nominaciones, lo fundamental es la concepción sistémica del cerebro que implican y la idea de que el cerebro en su conjunto supone el sistema último y total de la organización neuronal, sede de la mente, del yo, de la conciencia y del sujeto humano.

Los engramas, como subsistemas cerebrales, están siempre activados, y forman estructuras estables que facilitan y agilizan la tarea perceptora y de respuesta del cerebro a los estímulos tanto externos como internos al organismo. Estos rasgos de los engramas son la base de la memoria y del aprendizaje, dotando al ser vivo de una mayor eficacia de cara a la adaptación al medio y a la supervivencia. Como hace notar Monserrat, no todo engrama es el soporte de los qualia, puesto que tenemos la experiencia de que en nuestro sistema nervioso se producen experiencias físicas que son inconscientes, de tal forma que muchos de los engramas neuronales sirvieron a la supervivencia de los seres vivos antes de que emergiera la conciencia. La cuestión está, por tanto, en ver qué condiciones necesita un engrama o subsistema neuronal para general experiencia de autoconsciencia. Ese es el gran reto de las ciencias del cerebro. Pero también es importante advertir que «no sería, sin embargo, correcto pensar que los engramas se dividen en productores y no productores de qualia, yendo unos por una parte y otros por otras, o situándose unos en módulos cerebrales localizados, completamente aislados de los otros. Los qualia, la experiencia psíquica consciente, ocurren al estar activados ciertos engramas que los producen; pero la activación específica es, digamos, la punta del iceberg de una complejísima pirámide de engramas que van activándose y desactivándose como infraestructura inconsciente, mecánica, automática, que se constituye en soporte neuronal de los engramas finales productores de la conciencia ${ }^{109}$.

En definitiva, el cerebro es un complejo sistema de redes neuronales, capaces unos de producir conciencia mientras que otros funcionan de forma automática. Centrándonos en los engramas que producen conciencia, volvemos a repetir que la neurociencia no sabe explicar qué tienen de específico (como condición necesaria y suficiente) determinados engramas para que sean capaces de hacer emerger los qualia. Este es el problema central en la actualidad y la tarea más difícil del problema psico-físico. ¿Por qué el psiquismo, la conciencia, surge de determinadas estructuras neuronales?

Frente a los dualismos y a los reduccionismos materialistas, ya hemos señalado que el emergentismo sitúa la explicación de la mente humana en la compleja sistematización del cerebro, de este tipo de cerebro biológico que poseemos los humanos. Ahora bien, dentro de la postura emergentista, se están produciendo desde algún tiempo dos planteamientos diferentes, que aunque en ocasiones se presentan como dos vías opuestas e incompatibles, son perfectamente complementarios.

109 Ibídem, p. 189. 


\subsubsection{La mecánica cuántica y la emergencia de la conciencia.}

Monserrat advierte que las estrategias de investigación, y las propuestas de solución de los estudiosos del cerebro, también dentro del paradigma emergentista, se orientan en varias direcciones. Las dos más importantes son la que el propio Monserrat denomina vía de la neurología macroscópico-clásica, porque considera que la clave está en el nivel de las neuronas y en sus interconexiones sinápticas, y la vía de la neurología microfísico-cuántica, que sitúa el punto de mira de su investigación en niveles inferiores a las neuronas para fijarse en el ámbito de sus partículas elementales, donde se producen determinados sucesos cuánticos, que nos llevarían a situar ahí la emergencia de las experiencias cualitativas de conciencia ${ }^{110}$. Uno de los autores más significativos de esta segunda vía de investigación es $\mathrm{R}$. Penrose ${ }^{111}$. La vía macroscópico-clásica se halla ante la dificultad de explicar cómo de la estructura interneuronal, regida por leyes determinísticas, puede emerger una realidad como la conciencia humana, dotada de creatividad y libertad. Esta dificultad estaría supuestamente superada por la vía microfísico-cuántica, que basa sus investigaciones en situar en el ámbito interno de las neuronas, en concreto, como es el caso de Penrose, en los denominados microtúbulos, los fenómenos cuánticos que darían lugar al surgimiento de los fenómenos de conciencia, posibilitados por las leyes de la mecánica cuántica, constituidas por la indeterminación y la probabilidad. Claro que esta vía de investigación es pura hipótesis de trabajo, que tendrá que ser confirmada o rechazada por los avances de la neurofisiología. Pero, en principio, puede resultar plausible tal hipótesis y resultar fecunda de cara a posibilitar diversos caminos de investigación. Ahora bien, como el mismo Monserrat señala, el aspecto más crítico de esta teoría está precisamente en su operatividad científica, porque la verificación de los supuestos estados cuánticos en donde se daría el salto de lo físico a la conciencia resulta difícil de situar, y la puesta en práctica de tales experimentos de momento resulta muy costosa y difícil ${ }^{112}$. Pero entiende que no hay que cerrarse en principio a esta vía de experimentación, por lo sugerente que resulta conectar el ámbito indeterminista de lo cuántico con el problema de la conciencia.

110 Cfr. Ibidem, pp. 191-195.

111 Cfr. Penrose, R., The Emperor's New Mind: Concerning Computers, Minds, and the Law of Physics , Oxford University Press, 1989 (trad. cast.: La nueva mente del emperador, Grijalbo, Barcelona, 1996); Id., Shadows of the Mind: A Search for the Missing Science of Consciousness, Oxford University Press, 1994 (trad. cast.: Las sombras de la mente, Grijalbo, Barcelona, 1996); id., The Large, the Small and the Human Mind, Cambridge University Press, 1997 (trad. cast.: Lo grande, lo pequeño y la mente humana, Cambridge University Press, Madrid, 1999); SEArle, J., El misterio de la conciencia, Paidós, Barcelona, 2000, cap. 4, «Penrose, Kurt Gödel y los citoesqueletos», 57-91; Monserrat, J., "Penrose y la mente computacional», Pensamiento, 55 (1999) 177-216; Id., "Penrose y el enigma cuántico de la conciencia», Pensamiento, 56 (2000), 177-208; Id., «John Searle en la discusión sobre la conciencia», o.c.

112 Cfr. Monserrat, J., Engramas neuronales y teoría de la mente, o.c., pp. 193-194. 
De ahí que Monserrat se posicione de forma clara, aunque crítica y cuidadosa, a favor de las propuestas de Penrose, frente a la postura de J. Searle y otros críticos, más propensos a considerar las propuestas de la neurología cuántica como demasiado fantasiosas y sin fundamento ${ }^{113}$. Entiende Monserrat que la tesis de Penrose, appyado en las investigaciones de Hameroff ${ }^{114}$, es un modelo de interpretación y de investigación, y, por tanto, tiene que avanzar en sus concreciones y ser confirmado o no por la investigación científica ${ }^{115}$. Pero eso es normal al inicio de cualquier propuesta científica y filosófica.

La cuestión central del problema psico-biológico es, ya lo hemos dicho repetidas veces, cómo explicar la base biológica del cerebro dé lugar al mundo psíquico de la mente. Este mundo está conformado por una serie de características que son muy diferentes a las de su base biológica cerebral. Las propiedades del psiquismo, que, como indica Monserrat, las percibimos desde la introspección fenomenológica, son la experiencia campal u holística (esto es, la unidad campal de la conciencia) y la experiencia de la indeterminación y de la libertad. En la medida en que todas las evidencias apuntan a que estas cualidades se deben al soporte cerebral, la ciencia tiene que explicar cómo desde las propiedades cerebrales emergen las cualidades psíquicas. La propuesta general del emergentismo, como hemos visto, se centraba en los engramas neuronales, los específicos y complejos sistemas con que el cerebro humano está conformado. Pero resulta difícil explicar desde ese punto de vista tanto la unidad de la psique, como su libertad. La propuesta de Penrose nos hace ver que esta perspectiva emergentista, anclada en el nivel de los fenómenos mecanoclásicos, es insuficiente, por lo que es preferible y más fructífero orientar las investigaciones hacia el nivel de los fenómenos cuánticos ${ }^{116}$. Eso no significa que el nivel de los fenómenos mecanoclásicos no tenga que ser considerado válido, sino que la explicación de lo psíquico hay que situarla en «un equilibrio balanceado entre propiedades de interacción clásicas y cuánticas; equilibrio regido por un interface funcional (un mecanismo de tránsito de lo clásico a lo cuántico, y viceversa) que habría sido diseñado por la misma evolución» ${ }^{117}$.

113 Cfr. MonserRat, J., «John Searle en la discusión sobre la conciencia», o.c.

114 Cfr. Hameroff, Stuart, "Conscious Events As Orchestrated Space-Time Selections», Journal of Consciousness Studies, 3 (1996), 1, 36-53; Id y Roger Penrose, "Orchestrated Reduction of Quantum Coherence In Brain Microtubules: A Model for Consciousness», Toward a Sciences of Consciousness, The First Tucson Discussions and Debates, eds. Hamerroff, S. R., Raszniak, A. W. and Scott, A. C., Cambridge, MA: MIT Press, pp. 507-540; Id, "Quantum Computation In Brain Microtubules? The Penrouse-Hameroff "Orch OR" Model of Consciousness», Philosophical Transactions Royal Society London (A), 356 (1998), 1869-1896.

115 Cfr. Monserrat, J., «Penrose y la mente computacional», o.c., y «Penrose y el enigma cuántico de la conciencia», o.c.

116 Cfr. Penrose, R., La nueva mente del emperador, Madrid, Mondadori, 1991; Id., Las sombras de la mente, Barcelona, Crítica, 1996; Id., Lo grande, lo pequeño y la mente humana, Madrid, Cambridge University Pres, 1999.

117 Monserrat, J., Dios y religiones en la Era de la Ciencia, texto del Seminario impartido en la Universidad de Deusto, en tres sesiones, durante el curso 2013-2014, tercera sesión, p. 
Este modo de enfocar el problema supone que la visión clásica y la cuántica forman un sistema unitario en los seres vivos, de modo que la imbricación entre los dos niveles permitiría complementar la visión clásica de las redes neuronales con la propuesta de la neurología cuántica, que se orienta a mostrar dónde y cómo lo cuántico ha instalado sus nichos de existencia en el interior de la dimensión clásica. El estudio evolutivo de la vida nos muestra que de la materia no viva ha emergido la vida, dotada de sensibilidad, aunque no se sabe explicar desde lo físico cómo surgen las propiedades sensibles. Hay que deducir, por tanto, que la ontología de la materia no muestra todas sus virtualidades en el nivel de lo mecanoclásico. Y lo mismo cabe decir, y en mayor medida, en la aparición de la mente y la conciencia. La ciencia no hace más que constatar el hecho, pero no sabe explicarlo. La visión de la neurología clásica tiende a apoyarse en los parámetros de la física clásica, y mostrar una imagen de la psique y del ser humano determinista y mecánica. En cambio, la mecánica cuántica nos abre a un mundo abierto e indeterminado, que permite conformar una neurología cuántica, capaz de explicar las cualidades específicas del psiquismo: unidad y libertad. La mecánica cuántica nos ha mostrado una serie de propiedades extrañas de la materia, como son la coherencia cuántica, la superposición cuántica, la indeterminación cuántica y la acción-a-distancia o causación no local (efectos EPR) ${ }^{118}$. De este modo, se advierte que la materia posee, en si nivel cuántico, propiedades que no se cumplen en el nivel macroscópico clásico. Podemos decir que la materia cuántica ha sido atrapada o colapsada en la formación de los cuerpos clásicos, que no poseen ya la coherencia cuántica y demás cualidades de la materia primordial. Pero eso no significa que la materia no siga teniendo esas cualidades, en el nivel cuántico.

En esta dirección se sitúa la propuesta de la neurología cuántica que proponen R. Penrose y Stuart Hameroff para explicar el problema de la mente. Esta neurología cuántica, como indica Monserrat, "es la investigación sobre las propiedades cuánticas más primordiales de la materia con el fin de relacionarlas con el sistema neuronal a fin de establecer un adecuado "soporte físico" para explicar el contenido de las propiedades fenomenológicas del psiquismo (aquí nos hemos centrado en la experiencia campal holística y en la indeterminación)»119. Es importante advertir que la neurología cuántica no rechaza la clásica, sino que trata de complementarla, consciente de sus insuficiencias. La neurología cuántica entiende que la explicación de las propiedades de lo psíquico puede tener su origen (su soporte físico) en las propiedades primordiales de la materia cuántica. "La hipótesis, por tanto, sería que el "soporte físico" del mundo psíquico debería responder a la dualidad de dimensiones de la realidad física que la ciencia ha descrito: la clásica y la cuántica, dentro de su armonía de fondo en el marco de una explicación monista y evoluti-

\footnotetext{
20 (texto sin publicar).

118 Cfr. Ibidem, pp. 24-25.

119 Cfr. Ibídem, p. 26.
} 
va del universo. La hipótesis sería, por tanto, la búsqueda de una explicación «balanceada» entre lo clásico y lo cuántico. Esta explicación clásico/cuántica de los seres vivos sería más conforme con nuestra idea científica actual de la realidad física que también es clásico/cuántica» ${ }^{120}$.

La imagen de diferenciación y discontinuidad, mecánica y determinística, que nos muestra la imagen del mundo clásico (propio de la materia fermiónica), no es suficiente para explicar las propiedades del psiquismo. En cambio, sí lo permite la visión de la realidad cuántica, con sus propiedades de continuidad y campalidad, propias de la dimensión bosónica de la materia, que permiten entenderla como soporte físico de las cualidades del psiquismo: la unidad de la conciencia, la experiencia holística de los campos de la realidad y de la elección, y la indeterminación que permite la libertad. Esta es la hipótesis que en su momento defendió David Bohm, y en la actualidad, Penrose y Hameroff. Como indica Monserrat, «esta hipótesis pretende establecer conjeturas, argumentadas teórica y empíricamente, sobre la forma en que los estados cuánticos se habrían abierto un nicho ecológico dentro del cerebro y permitirían que, en el sistema clásico del cerebro, anidaran sistemas de interacción de la materia que respondieran a las propiedades cuánticas» ${ }^{121}$.

Y entrando en concreciones, Penrose y Hameroff entienden que el lugar clave de esta interacción entre el nivel clásico y el cuántico se produce, dentro del cerebro, en el ámbito de los microtúbulos del citoesqueleto nuclear, presentes en todas las neuronas. Según esta hipótesis, este sistema de microtúbulos podría reunir las cualidades físico-biológicas que permitieran producirse en ellos fenómenos de coherencia cuántica. De la misma forma, el estado cuántico de coherencia en el que se encontrarían los múltiples microtúbulos, formarían un sistema unitario de coherencia con otros microtúbulos, abarcando un amplio sistema de neuronas y gran parte del cerebro ${ }^{122}$.

Según estos planteamientos, "la conciencia sería así el correlato de estos estados cuánticos globales construidos a partir de los microtúbulos. A estos estados cerebrales en coherencia cuántica se les debería atribuir una "función de onda" susceptible de estar en "superposición cuántica” (estar en varios estados al mismo tiempo y no estar en ninguno). En ciertos momentos, sin embargo, se produciría el "colapso de la función de onda". La hipótesis Hameroff-Penrose postularía que los estados de conciencia (y los qualia en ellos producidos, por ejemplo, en una imagen visual) serían el correlato psíquico

120 Ibidem, p. 27.

121 Ibidem, p. 27.

122 Cfr. Ibídem, p. 27. Para ver más a fondo la realidad del citoesqueleto nuclear y de los microtúbulos, cfr. las obras de Penrose ya citadas y los trabajos de Monserrat sobre Penrose arriba citados. Cfr. Monserrat, J., «Introduction to Finale Debate. Holistic Aproach in Biology and Neuroscience», Pensamiento, 67 (2011), n ${ }^{\circ}$ 254, Serie Especial, n ${ }^{\circ}$ (2011), pp. 733-743; Castro García, O., "Aspectos biosemióticos de la conciencia. En búsqueda de los signos de la vida y su referencia a la conciencia como principio teleonómico», Pensamiento, 62 (2006), n n $^{\circ} 34$, pp. 471-504. 
resultante de la entrada en coherencia/decoherencia cuántica de grandes cantidades de los microtúbulos, diversificados en diversos módulos cerebrales, por acción-a-distancia, causación no-local (o efectos EPR, así llamados en mecánica cuántica desde el experimento imaginario de Einstein, Podelsky y Rosen en 1935)» ${ }^{123}$.

Estas propiedades cuánticas permiten aceptar mejor al cerebro como soporte físico de la psique y de la conciencia, en la medida en que la experiencia fenomenológica que tenemos del sujeto psíquico nos lo muestra dotado de unidad y libertad. Ello se debería a que «los estados cuánticos cerebrales estarían en superposición cuántica y se mantendrían abiertos a posibles colapsos de la función de onda del sistema. El sujeto podría inducir el colapso de la función de onda de una manera flexible, permitiendo, de una forma u otra, el control de los mecanismos mecanoclásicos del movimiento. Es decir, el control de una forma u otra de las redes clásicas de engramas neuronales. Este sería el origen de la experiencia subjetiva consistente en que el sujeto psíquico tiene la persuasión de ejercer una causalidad descendente que le permite tener un dominio de los mecanismos clásicos del cerebro de que dependen la conducta y la actividad mental. La mente controla el movimiento y controla el pensamiento o el flujo de la conciencia, que diría James»124.

Como ya hemos repetido varias veces, esta propuesta de neurología cuántica no supone la negación de las referencias al nivel mecanoclásico de los engramas neuronales, sino que propone una visión sistémica, en la que se armonizarían la visión clásica con la cuántica. En realidad, los seres vivos no podrían ser entendidos ni ser viables sin una interacción de estos dos niveles, actuando el mundo externo sobre los sistemas neuronales y microtubulares, para producir las sensaciones de la actividad psíquica, y constituyéndose el sujeto psíquico desde la superposición cuántica, controlando sus formas de colapso que permiten las acciones voluntarias y el control de la decisiones descendentes del sujeto (de la mente a las respuestas al entorno). Se produce, de este modo, un interface bidireccional, ascendente (apertura al mundo sensitivo) y descendente (respuestas del sujeto a los estímulos) ${ }^{125}$.

Monserrat es consciente de las debilidades de la hipótesis de Penrose-Hameroff, como lo muestra en el análisis valorativo y crítico que realiza al final de escritos donde presenta estas teorías ${ }^{126}$. Pero, aunque considere que estas tesis se hallan «en el filo de la especulación», entiende que es inevitable para el avance de la ciencia empezar por proponer propuestas especulativas que luego la experimentación científica las puede rechazar o confirmar. Y en este caso, la propuesta de Penrose-Hameroff se halla confirmada por el conjunto de la mecánica cuántica y resulta la más creativa y sugerente para seguir avan-

123 Monserrat, J., Dios y religiones en la Era de la Ciencia, o. c., pp. 27-28.

124 Ibídem, p. 28.

125 Cfr. Ibídem, p. 28.

126 Cfr. «Penrose y la mente computacional», o.c., pp. 196-208; «Penrose y el enigma cuántico de la conciencia», o.c., pp. 195-208. 
zando en el problema psico-físico, en la medida en que abre un horizonte de posibilidades nuevas en este campo. Hasta ahora, las posturas que se daban a la hora de explicar la relación de la mente con el cerebro, y el cuerpo en su globalidad, se debatían entre el dualismo y el reduccionismo materialista. Pero estas posturas extremas no se compaginaban de forma adecuada con nuestra experiencia fenomenológica, abocando por el lado del dualismo en una concepción separada de la mente, con dificultades a la hora de explicar la causación descendente; y, por otro lado, el reduccionismo nos abocaba a una concepción del sujeto humano mecanicista y determinista, reduciendo al ser humano a un robot. Esta deriva reduccionista es la que ha empujado a muchos científicos y filósofos, entre los que hay que contar a Penrose, a proponer posturas alternativas e intermedias, como son las emergentistas.

El emergentismo, a diferencia del dualismo, entiende que el soporte físico de la mente es el cerebro, por lo que se define su planteamiento como teoría monista, no siendo necesario defender el dualismo para mantener una visión humanista del ser humano. Por otro lado, a diferencia del reduccionismo, emergentismo no reduce lo mental al mero funcionamiento biofísico del cerebro, sino que lo mental es la nueva estructura o sistema como está conformado el cerebro humano, fruto del largo proceso evolutivo. Pero, como ya lo hemos visto, la propuesta de los emergentismos clásicos, centrados solamente en la dimensión mecanoclásica de los engramas o subsistemas cerebrales, no es suficiente, sino que tenemos que proponer una visión integral de la neurología, clásica y cuántica. De este modo, con este enfoque holístico de la neurología cuántica, se refuerza la visión monística, armónica y evolutiva del cerebro, de la biosfera y del universo. Así, «esta imagen monista del universo en la nueva física holista entiende la realidad física de manera que se hace inteligible que sus propiedades hayan podido producir la emergencia de la sensación-percepción-conciencia» ${ }^{127}$.

Pero hay que ser conscientes de que estos avances científicos lo único que muestran, de momento, es cómo es de hecho el universo, pero no han logrado todavía explicar las leyes profundas de su funcionamiento. Lo que nos muestra todo esto, como señala Monserrat, es que la materia de que está hecho el universo posee una ontología capaz de producir la sensibilidad y la conciencia, en el momento evolutivo que le corresponda. La ciencia no hace más que constatar hechos a posteriori. Las propuestas de explicación a priori le corresponde a la metafísica filosófica. Aunque los avances de la ciencia ayudan a la metafísica a entender mejor una visión profunda de la realidad. De este modo, la mecánica y la neurología cuánticas nos hacen más fácil entender que, en el desarrollo evolutivo de la materia viva, haya un momento en el que emergen tanto la sensibilidad como la conciencia y el sujeto humano ${ }^{128}$.

127 Monserrat, J., Dios y religiones en la Era de la Ciencia, o. c., p. 29.

128 Cfr. Ibídem, p. 29-30. 


\subsection{La emergencia de la conciencia como proceso de hiperformalización}

Las propuestas emergentistas que hemos visto, se sitúan primordialmente en el terreno de la hipótesis científicas, y, por ello, Monserrat completa su reflexión desde un horizonte filosófico en el que sitúa el conjunto del proceso de hominización y un modelo antropológico humanista. El emergentismo resulta coherente con diversas teorías antropológicas sobre el proceso de hominización, coronadas con la tesis zubiriana de la hiperformalización, como modelo explicativo de todo el proceso evolutivo ${ }^{129}$. La historia de la hominización se apoya en etapas evolutivas previas dentro de la historia de la biosfera, que tienen como capítulo precedente la etapa de la mente animal, desde la que emergió la mente humana. Como ya lo hemos indicado, la cuestión que no hemos resuelto todavía es cómo se ha producido esta emergencia de la conciencia, como factor determinante del proceso de hominización. Monserrat considera que las respuestas que se ha dado a esta cuestión son varias y plurales, aunque no necesariamente opuestas, sino complementarias.

Las teorías que le resultan más interesantes son la teoría de la deficiencia e inespecialización biológicas que defiende A. Gehlen ${ }^{130}$, para quien la razón humana y sus frutos, la cultura, han nacido como fuerza evolutiva que ha tenido que compensar la deficiencia biológica de la especie humana. Junto a este enfoque antropológico, Monserrat destaca también la teoría del trabajo propia del marxismo, para quien «la inteligencia racional específicamente humana surgió como exigencia de la actividad laboral que desarrollaron los homínidos que habían alcanzado ya la posición erecta» ${ }^{131}$. Una tercera teoría, la sociolingüística, propuesta por prestigiosos paleoantropólogos modernos, defiende que la aparición del lenguaje, en el contexto de las relaciones sociales, fue el proceso fundamental que determinó el nacimiento de la inteligencia y la razón humana ${ }^{132}$. Por su parte, ciertos etólogos prestigiosos, como K. Lorenz y R. Rie$\mathrm{dl}$, han defendido que la inteligencia humana es el resultado de los esfuerzos de la especie humana en su adaptación biológica y conductual. En esta teoría se conjugan las tesis sobre la biología del conocimiento de R. Riedli133, con las de K. Lorenz sobre los mecanismos que rigen la conducta de las diferentes especies animales, que van desarrollando una estrategia de progresivo esfuerzo para adaptarse al entorno ambiental ${ }^{134}$.

129 Cfr. Monserrat, J., La percepción visual, o.c., pp. 558 y ss.; cfr. Id., Hacia el nuevo Concilio, o.c., pp. 266 y ss.; Id., Dios y las religiones en la Era de la Ciencia, o.c., pp. 38 y ss.

130 Cfr. Gehlen, A., El hombre. Su naturaleza y su lugar en el cosmos, Salamanca, Sígueme, 1980 .

131 Monserrat, J., La percepción visual, o.c., p. 559. Un texto clave para ver esta teoría es el de A. Spirkin, El origen de la conciencia humana, Buenos Aires, Edit. Platina/Stilcograf, 1965.

132 Cfr. Monserrat, J., La percepción visual, o.c., pp. 559-560.

133 Cfr. RiedL, Rupert, Biología del conocimiento. Los fundamentos filogenéticos de la razón, Barcelona, Labor, 1983.

134 Cfr. Lorenz, K., La otra cara del espejo, Barcelona, Plaza y Janés, 1980. 
Estas diversas perspectivas antropológicas no son en absoluto excluyentes sino complementarias, y como coronación de las mismas sitúa Monserrat la tesis de la hiperformalización biológica de Zubiri. Tiene la ventaja de que es más completa y presupone también los elementos más valiosos de las teorías anteriores. Monserrat recoge los puntos básicos de la teoría zubiriana, pero completándola con aportaciones propias. Nos hace ver, de entrada, que se trata de un constructo teórico, un sistema complejo de suposiciones hipotéticas, pero que se apoya en suficientes elementos empíricos, propios de la teoría evolucionista, de la etología y de las neurociencias, como para que no resulte correcto afirmar que se trata de una hipótesis gratuita. La evolución nos muestra que en el mundo animal se ha producido una progresiva complejización del sistema cognitivo, dotando a las diferentes especies vivas de una mayor capacidad de captar y dominar la realidad. En ese proceso evolutivo, la aparición del linaje humano es consecuencia de una hiperformalización cerebral y cognitiva, que ha generado una mayor capacidad de aprehensión perceptiva de los objetos, esto es, una hiperobjetivación. Como consecuencia de ello, en el ser humano se da una aprehensión sensible de la realidad, mientras que a los animales se les presenta la realidad como mera fuente de estímulos. En definitiva, a los humanos se les da, como modo de conocer, como habitud, la realidad en cuanto tal (formalidad de realidad), mientras que a los animales, la realidad se les da bajo la formalidad de estimulidad. En definitiva, entre los grandes simios y el ser humano se habría producido un salto cualitativo, emergente, fruto de dicha $h i$ performalización, por el que la realidad se les presenta a ambos tipos de vida de forma cualitativamente diferente. La formalidad de realidad con que percibe la realidad el ser humano le hace ver lo real como estructura, como conjuntos de notas que forman las diferentes sustantividades, las cosas reales, constituidas por unidades de notas con suficiencia entitativa para existir. Y dentro de la capacidad intelectiva del ser humano, la intelección sentiente, Zubiri considera que se dan tres momentos estructurales: la impresión primordial de realidad, el logos y la razón, como capacidad suprema de dejarse arrastrar por la realidad, que le da que pensar y le empuja a la búsqueda de la esencia de las cosas y del fundamento último de la realidad. Según esto, la razón es la capacidad del ser humano de ir de lo fenoménico, lo que se ve y percibe por los sentidos, a lo trans-fenoménico, las representaciones racionales, la esencia de las cosas y de la realidad, su verdad última ${ }^{135}$.

Como bien afirma repetidas veces Monserrat, esta teoría «es un macroconstructo hipotético, una conjetura: un sistema complejo de suposiciones e hipótesis que, si se hubieran cumplido, explicarían cómo se ha producido la emergencia evolutiva del conocimiento. Sin embargo, estas hipótesis no son gratuitas, ya que hay un conjunto de hechos empíricos y teorías científicas que hacen altamente verosímil que las cosas sucedieran realmente tal como esta teoría supone. Estos hechos y teorías previas ya han sido establecidos por

135 Cfr. Monserrat, J., La percepción visual, o.c., pp. 560-564. 
disciplinas científicas como la biología, la neurología, epistemología, etología, psicología, etc.» ${ }^{136}$.

Todos estos planteamientos constituyen, además, para Moserrat elementos más que suficientes como para defender una concepción antropológica humanista y una visión creyente, cristiana, de la realidad. Las teorías reduccionistas de la filosofía de la mente no garantizan una concepción del ser humano como sujeto libre y responsable de su vida y de su realización como persona, dentro de una dimensión interpersonal y social ineludible. La teoría emergentista y la tesis de la hiperformalización de Zubiri permiten, por su parte, defender una idea del sujeto humano que conjuga tanto su incardinación dentro del proceso evolutivo, como también su diferencia cualitativa respecto del mismo, en la medida en que tanto su condición epistemológica, como ontológica y ética, se sitúan en una dimensión diferente como sujeto autoconsciente, libre y responsable de los demás.

Y, por otro lado, estas bases científicas y filosóficas permiten también defender una metafísica abierta a la cuestión del fundamento de la realidad, a la idea de Dios como horizonte y apoyo último del universo. Es evidente que las propuestas de la nueva física, de la biología evolucionista, así como las de las neurociencias, permiten deducir tanto una metafísica atea, agnóstica como creyente. Pero, en opinión de Monserrat, «creemos que esta nueva física holística hace también mucho más verosímil que el fundamento metafísico y absoluto de la realidad pudiera ser un ser divino, tal como han creído las tradiciones religiosas que abarcan la historia de la humanidad. La ciencia nos lleva hoy a un campo fundante de la realidad que trata de entender con complejos conceptos "físicos" como vacío cuántico, mar de energía, geometría del espaciotiempo, orden implicado, etc. En este contexto, yendo más allá de los conceptos físicos, la imagen de una divinidad que constituye el fondo ontológico de toda la realidad, en la que nos movemos, existimos y somos, una realidad que, en último término, es un campo transparencial abarcado por la conciencia divina, nos acerca mucho más a la idea de que algo así como lo que las religiones han vivido como Dios, pudiera realmente existir» ${ }^{137}$.

\section{UN EMERGENTISMO HUMANISTA Y CREYENTE}

Hemos intentado poner de manifiesto los principales elementos que conforman la tesis emergentista humanista de J. Monserrat, dentro del amplio movimiento emergentista que cada vez resulta más plausible y aceptado. Si donde se ha hecho más conocida ha sido en el ámbito de las relaciones mente-cuerpo, hemos visto que sus pretensiones van más allá, y aspira a convertirse en una teoría que atraviesa todos los momentos de la historia del universo, así como

136 Id, Dios y las religiones en la Era de la Ciencia, o.c., p. 39.

137 Ibídem, p. 30. 
todos los ámbitos de la realidad: materia física, biología y neurología. Frente a las tesis materialistas reduccionistas, empeñadas en reducir las leyes del universo a la visión mecanicista de las leyes de la física y de la biología; y frente a los dualismos insuficientes y trasnochados, que echan mano de una sustancia espiritual que encuentra serios problemas para definirse y explicar sus relaciones con la materia, se propone el paradigma emergentista, apoyándose en una visión dinámica y holística del universo, como realidad en la que todo está relacionado, surgiendo todo desde la materia, en un despliegue dinámico, en el que van emergiendo y apareciendo diversas y progresivas sistematizaciones de la realidad. La materia no viva, en función de su propia ontología cuántica, da de sí la vida sensible, y posteriormente, la mente animal y la autoconciencia humana.

Es cierto que la hipótesis emergentista, aunque no constituye una teoría totalmente configurada y del todo contrastada con las evidencias empíricas, se ha constituido en una propuesta teórica y un programa de investigación que resultan muy ventajosos frente a todas sus teorías rivales. Y aumenta todavía más su atractivo si se la entiende desde la propuesta de Penrose-Hameroff, orientada a complementar el emergentismo sistémico, que hace referencia a los engramas neuronales para explicar la emergencia de lo mental, con el emergentismo de la neurología cuántica, que apela al citoesqueleto neuronal de los microtúbulos para situar el soporte físico de la mente, desde el supuesto de que es ahí donde se producen una serie de fenómenos cuánticos que hacen más plausible la naturaleza unitaria, holística y libre del psiquismo humano.

J. Monserrat, como hemos podido comprobar, ha sido desde el primer momento partidario de las tesis emergentistas, estudiando a fondo las propuestas de los principales representantes de esta postura, y presentando en profundos y precisos artículos las ideas más importantes de Searle, Edelmann, Krick, Damasio, y sobre todo de Penrose. Si ha defendido con convicción el emergentismo sistémico que situaba la razón de la emergencia de la mente en la sistematización progresiva de las redes neuronales, ha sido también uno de los más firmes defensores de la neurología cuántica propuesta por Penrose y Hameroff, analizando detenidamente sus propuestas, valorándolas en lo que tienen de defendibles, así como señalando claramente aquellos aspectos que no le han resultado del todo convincentes.

En todos estos trabajos de reflexión sobre las propuestas emergentistas, J. Monserrat ha mostrado una amplia capacidad para estar al día en los avances más punteros de este paradigma, así como una maestría especial a la hora de situar estas propuestas en el horizonte del conjunto de los saberes más avanzados de la biología, la epistemología, las ciencias de la visión, la neurología y la filosofía de la mente. De ese modo, Moserrat se presenta como uno de los intelectuales más capacitados de nuestro entorno intelectual, mostrando un completo conocimiento de los avances científicos, como también una capacidad de construir un ambicioso sistema antropológico y metafísico. De este modo, la propuesta intelectual de Monserrat no se ha limitado a mostrar las más 
avanzadas propuestas teóricas de la teoría emergentista, sino también el modelo humanista del ser humano que dentro de tal paradigma se puede construir.

Está claro para J. Monserrat que las tesis emergentistas permiten más que nunca, frente al cada vez más defendido y extendido materialismo reduccionista, dentro de muchos entornos científicos y filosóficos, presentar de la forma más ventajosa la relación de la conciencia con su suporte físico, el cerebro. Estos enfoques están teniendo cada vez más apoyos y defensas tanto en el ámbito científico como filosófico. De este modo, Monserrat es consciente de que con este paradigma se hace cada vez más plausible la posibilidad de defender una imagen humanista del ser humano, entendiéndolo como una realidad anclada y enraizada en el proceso evolutivo, pero, al mismo tiempo, dotada de una serie de rasgos y de potencialidades, como la autoconciencia y la libertad, que lo sitúan en un nivel cualitativo diferente al resto de las demás realidades del universo.

Y también, como dejamos señalado en su momento, el paradigma emergentista le permite a J. Monserrat entender la imagen del universo que nos proyectan tanto las nuevas ciencias como la filosofía actuales, imagen que se nos presenta como un campo transparencial, abrirnos y atisbar tras él una concepción metafísica que nos empuja a la pregunta por Dios como fundamento último de todo lo que hay. Los saberes científicos son neutros respecto a la fe, en la medida en que no pueden demostrar ni la existencia de Dios ni tampoco su no existencia, pero, por ello mismo, nos posibilitan a la vez que nos dejan libres para proponer, junto a otras metafísicas alternativas, una visión teísta de la realidad, bien cimentada y facilitada por las nuevas aportaciones científicas.

En resumen, el modelo de reflexión científica y filosófica de J. Monserrat constituye un excelente ejemplo sobre cómo podemos reflexionar en los tiempos presentes, atentos a los avances científicos, rigurosos a la hora de situar epistemológicamente cada parcela del saber en su sitio legítimo, y empujados por la pasión de seguir defendiendo un modelo humanista del ser humano ante tantas imágenes del mismo que, o bien le niegan su diferencia ontológica, o lo sitúan al margen de la realidad de nuestro mundo. Y todo ello sin renegar de las propias convicciones religiosas, que lejos de estar siendo superadas por los avances científicos y filosóficos (aunque algunos se empeñan en afirmarlo), se hallan cada vez más posibilitadas por ellos, si se sabe dialogar de forma inteligente y autocrítica. Por todo ello, la lectura de las obras de Monserrat se convierte en una excelente apertura a lo más avanzado de los saberes del momento, así como un modo muy positivo de afianzarse en las convicciones humanistas y en la pertinencia de poder seguir siendo cristiano en una época y cultura tan secularizadas como la nuestra, y en las que el silencio de Dios parece hacerse cada vez más denso, aunque, por otro lado, también más luminoso y sugerente. 